\title{
Design Requirements for Ultrasonic Deformation Sensor for TREAT Experiments
}

Joshua Daw, Anthony Crawford, Richard Skifton, Lance Hone, Pradeep Ramuhalli, Richard Jacob, Andrew Cassella, Robert Montgomery

June 2018

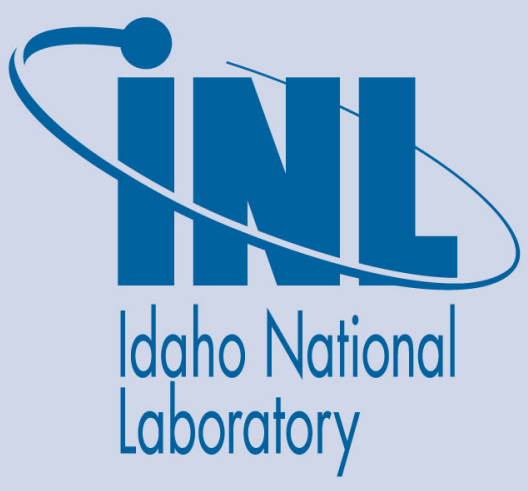

The INL is a U.S. Department of Energy National Laboratory operated by Battelle Energy Alliance 


\section{Design Requirements for Ultrasonic Deformation Sensor for TREAT Experiments}

Joshua Daw, Anthony Crawford, Richard Skifton, Lance Hone, Pradeep

Ramuhalli, Richard Jacob, Andrew Cassella, Robert Montgomery

June 2018

Idaho National Laboratory Idaho Falls, Idaho 83415

http://www.inl.gov

Prepared for the

U.S. Department of Energy

Under DOE Idaho Operations Office

Contract DE-AC07-05ID14517 


\section{Design Requirements for Ultrasonic Deformation Sensor for TREAT Experiments}

Joshua Daw, Anthony Crawford, Richard Skifton, Lance Hone-INL Pradeep Ramuhalli, Richard Jacob, Andrew Cassella, Robert MontgomeryPNNL June 2018

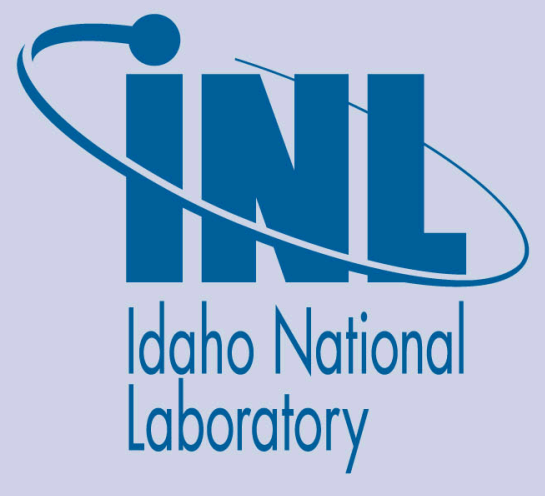

The INL is a U.S. Department of Energy National Laboratory operated by Battelle Energy Alliance 


\section{DISCLAIMER}

This information was prepared as an account of work sponsored by an agency of the U.S. Government. Neither the U.S. Government nor any agency thereof, nor any of their employees, makes any warranty, expressed or implied, or assumes any legal liability or responsibility for the accuracy, completeness, or usefulness, of any information, apparatus, product, or process disclosed, or represents that its use would not infringe privately owned rights. References herein to any specific commercial product, process, or service by trade name, trade mark, manufacturer, or otherwise, does not necessarily constitute or imply its endorsement, recommendation, or favoring by the U.S. Government or any agency thereof. The views and opinions of authors expressed herein do not necessarily state or reflect those of the U.S. Government or any agency thereof. 
INL/EXT-18-45209

Revision 0

\section{Design Requirements for Ultrasonic Deformation Sensor for TREAT Experiments}

Joshua Daw, Anthony Crawford, Richard Skifton, Lance Hone-INL Pradeep Ramuhalli, Richard Jacob, Andrew Casella, Robert Montgomery-PNNL

June 2018

Idaho National Laboratory

Pacific Northwest National Laboratory

Idaho Falls, Idaho 83415

http://www.inl.gov

Prepared for the

U.S. Department of Energy

Office of

Under DOE Idaho Operations Office

Contract DE-AC07-05ID14517 


\title{
Design Requirements for Ultrasonic Deformation Sensor for TREAT Experiments
}

\author{
INL/EXT-18-45209 \\ Revision 0 \\ June 2018
}

Approved by:

\section{Name}

Title [optional]

\section{Name}

Title [optional]

Name

Title [optional]

Name

Title [optional]

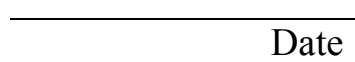

Date

\section{Date}




\section{SUMMARY}

This report is meant to be a guiding document for the development of an ultrasonic deformation sensor to be deployed in TREAT transient experiments. As such, information detailing the reactor, likely experiment capsules, and facilities have been included. Also, information on the required measurement

speed and resolution and design constraints have been documented through literature reviews and interactions with TREAT team leads. Development of this document has shown that although there are many potential applications, each with variations on design and needs, there are several basic constraints that need to be met for any application. The SETH capsule has been selected as a first target application, as it is planned for near term deployment, matches most of the design considerations of other planned capsules, and is designed to be used for sensor testing, along with fuel and material irradiations. 


\section{CONTENTS}

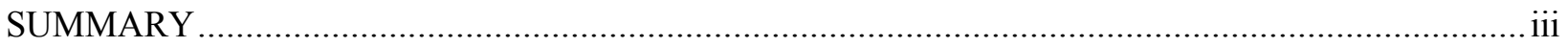

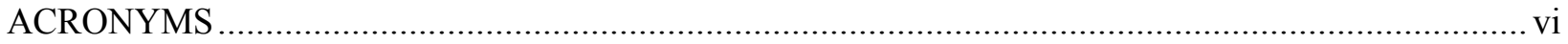

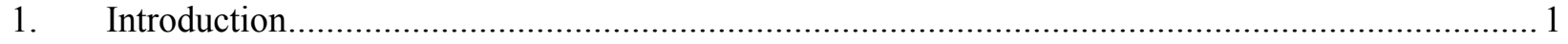

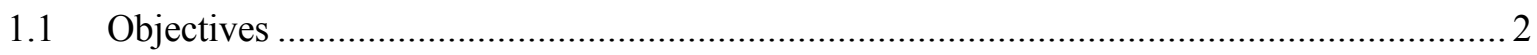

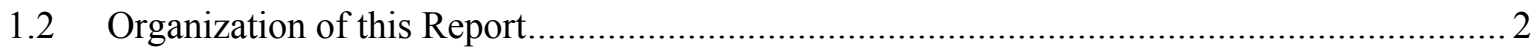

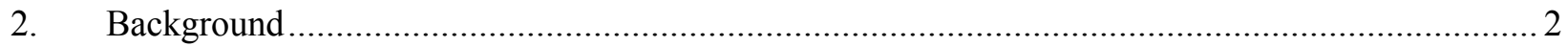

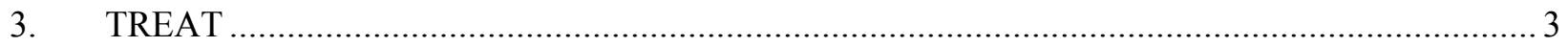

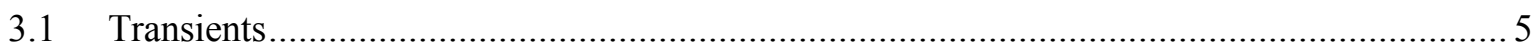

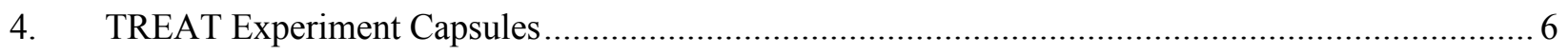

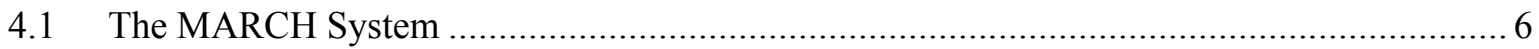

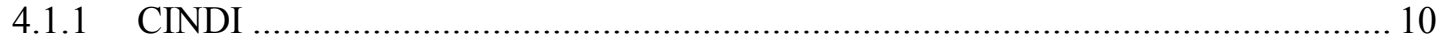

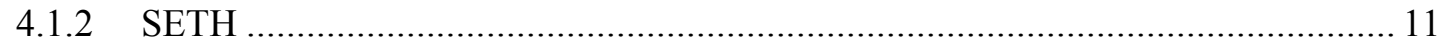

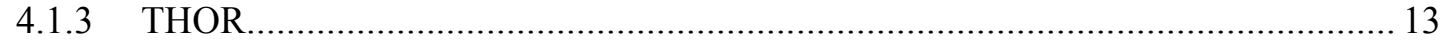

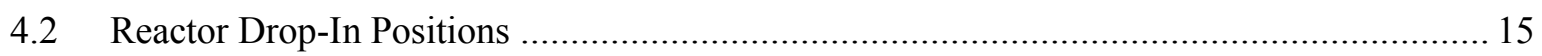

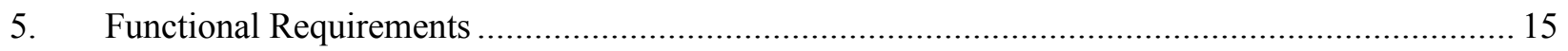

5.1 Review of Cladding Strain Measurement Requirements for TREAT Testing

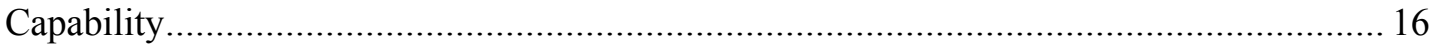

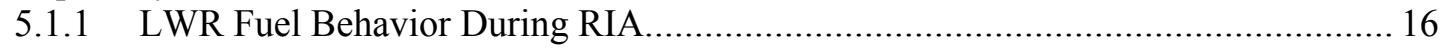

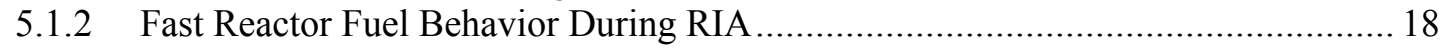

5.2 Dimensional Measurement requirements ............................................................... 20

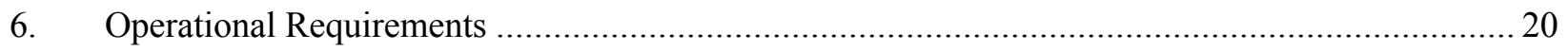

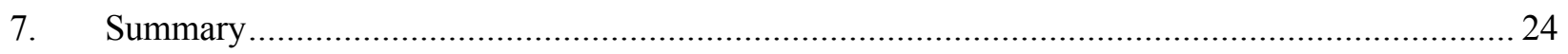

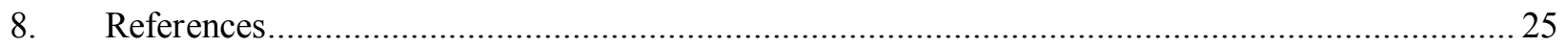




\section{FIGURES}

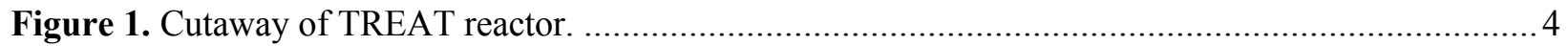

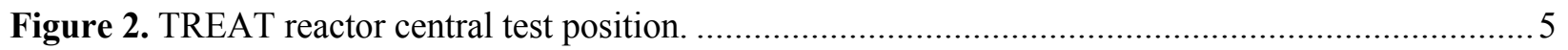

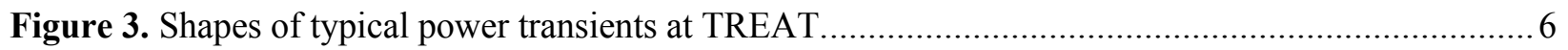

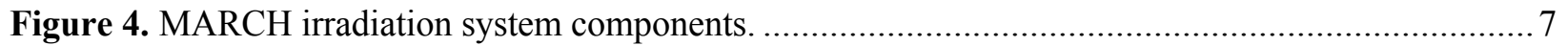

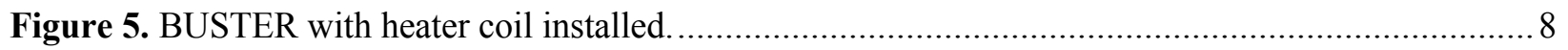

Figure 6. BUSTER secondary containment can and primary containment pipe. ................................ 9

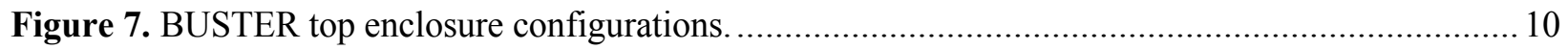

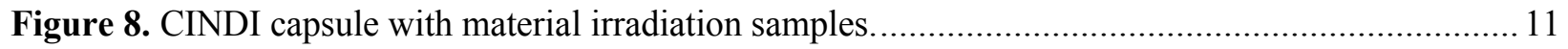

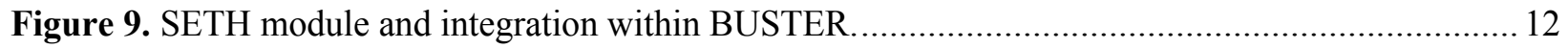

Figure 10. SETH capsule internal sensor supports and fuel pin surrogate .......................................... 13

Figure 11. THOR capsule schematic with sodium bonded fuel pin. ................................................. 14

Figure 12. Installation of instrument test rods in TREAT cooling channels...................................... 15

Figure 13. Schematic of Phase 1 and Phase 2 of the Clad Loading Process During an RIA Power Pulse. 17

Figure 14. Selected test results for fast reactor fuel, illustrating a typical sequence for initiating fuel pin failure (from [24])

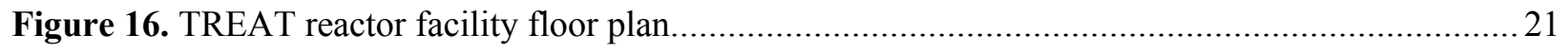

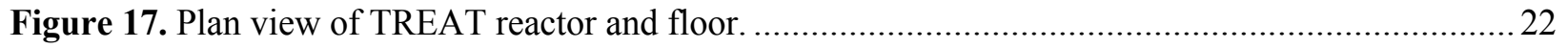

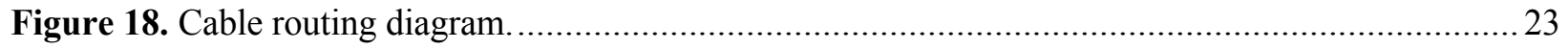

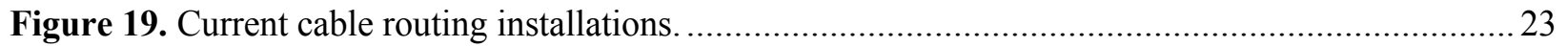

\section{TABLES}

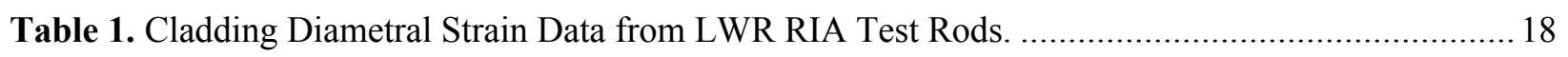

Table 2. Minimum requirements for SETH capsule sensor testing in TREAT..................................20 


\section{ACRONYMS}

BUSTER

CINDI

DAQ

DNB

DOE-NE

FR

LVDT

LWR

MARCH

NDE

NEET-ASI

NSRR

PCMI

PRF

PWR

PZT

RIA

SETH

SFR

THOR

TREAT
Broad Use Specimen Transient Experiment Rig

Characterization-scale Instrumented Neutron Dose Irradiation

Data Acquisition System

Departure from Nucleate Boiling

Department of Energy-Nuclear Energy

Fast Reactor

Linear Variable Differential Transformer

Light Water Reactor

Minimal Activation Retrievable Capsule Holder

Non-Destructive Examination

Nuclear Energy Enabling Technologies-Advanced Sensors and Instrumentation

Nuclear Safety Research Reactor

Pellet Cladding Mechanical Interaction

Pulse Repetition Rate

Pressurized Water Reactor

Lead Zirconate Titanate

Reactivity Initiated Accident

Separate Effects Test Holder

Sodium Fast Reactor

Temperature Heat-sink Overpower Response

Transient REActor Test Facility 


\section{Design Requirements for Ultrasonic Deformation Sensor for TREAT Experiments}

\section{Introduction}

The TREAT facility was specifically designed to conduct transient reactor tests to simulate conditions ranging from mild upsets to severe reactor accidents. Transient irradiation of nuclear fuel samples is performed to identify fuel performance limitations. Of particular interest is testing conducted on preirradiated fuel samples to determine end-of-life performance limits that typically dominate fuel design. A significant challenge in these tests is the deployment of instrumentation for quantifying fuel condition (such as temperature, thermal conductivity, and mechanical condition) while minimizing any changes in these conditions due to the presence of the sensor itself.

A host of instrumentation was used during the operation of TREAT between 1959 and 1994 [1] to generate data necessary for fuel performance quantification. Much of the instrumentation capability from the previous TREAT operations will need to be resurrected, and a significant development, qualification, and integration effort may be necessary before some of these measurement technologies can be redeployed. The unique operating characteristics of TREAT (short bursts of high energy radiation) also challenge many sensors and instrumentation that may otherwise be deployed in-pile in test reactors. Ongoing research and development is addressing several instrumentation needs for TREAT experiments, with details of these advances documented elsewhere [1-3].

Among the key parameters of interest for monitoring during transient tests is the deformation of each component of the fuel pin. While linear variable differential transformer (LVDT) transducers are a potential solution, the sensitivity and response times of these sensors may be limited. The size of typical LVDTs and need for a push-rod connected to the sample make them intrusive and difficult to use in a constrained environment (such as the test capsules proposed for use in TREAT [3]). In addition, typical LVDT sensors are limited in their ability to provide data on radial deformation of the fuel pins.

An ultrasonic measurement approach could enable rapid, accurate measurements of deformation in axial and radial directions in fuel pins during TREAT irradiation tests. This is the focus of the work described in this report.

The overall objective of this work is to design an ultrasonic sensor capable of rapid, non-contact, in-situ measurements of dimensional changes in pre-irradiated fuel during re-irradiation. Specifically, the proposed sensor design will target:

- Reliable operation at elevated temperatures (between $\sim 300^{\circ} \mathrm{C}$ and $600^{\circ} \mathrm{C}$ )

- Design compatibility with proposed near-term TREAT irradiation capsule concept designs [3]

- Direct measurement of fuel dimensional changes, including fuel rod diameter

- High-speed measurements to enable rapid characterization of changes during a transient test.

In addressing this research scope, we will leverage prior research in long-term piezoelectric sensor material survivability using in-pile sensor tests in materials test reactors (including previous NEET-ASI research) and in ultrasonic characterization of irradiated fuel specimens [4-7]. While irradiation (specifically, total dose) and time-at-temperature (especially above $\sim 600^{\circ} \mathrm{C}$ ) are not expected to be a significant issue during TREAT transient tests, the ability to design the sensor to withstand such environments will increase sensor and measurement reliability. Prior research in compensation techniques [8], and advances in measurement science including higher bandwidth instrumentation, high-speed data acquisition devices and low noise electronics enable increased accuracy and precision from ultrasonic measurements. Recent results from post-irradiation examination of irradiated fuel using commercial-offthe-shelf ultrasonic probes and instrumentation [9] also demonstrated the potential sensitivity of 
ultrasonic measurements to fuel dimensions (and potentially to microstructure) and the ease with which commercial ultrasonic probes and instrumentation can be applied to irradiated fuel.

\subsection{Objectives}

This report describes the functional and operational requirements for an ultrasonic sensor for monitoring fuel dimensions during a transient test. This is the first stage in the sensor design and testing process, as insights from previous transient tests, operational constraints derived from current TREAT capsule designs, and the operational environment during a TREAT transient test, will all need to drive the sensor design process. Subsequent reports will describe potential sensor design concepts and laboratory testing mechanisms that may be employed prior to potential sensor testing and evaluation at the TREAT facility.

\subsection{Organization of this Report}

Section 2 of this report briefly discusses background information on ultrasonic measurements. A brief description of TREAT is given in Section 3, with the various TREAT experiment capsules discussed in Section 4. Sections 5 and 6 describe the functional and operational requirements for the ultrasonic sensor based on previous post-irradiation examinations (PIE) of reactor fuel subjected to transient tests. The report is summarized in Section 7.

\section{Background}

Ultrasonic measurements of deformation can provide nondestructive measurements of dimensional changes rapidly (within tens to hundreds of microseconds). Further these methods are sensitive to both microstructural changes due to damage (from thermal, mechanical, and irradiation environments) and gross structural changes (such as swelling). As a result, ultrasonic methods have been applied to address needs in the nondestructive evaluation of structural components in nuclear power plants (including fuel cladding) during periodic pre-service and in-service inspection inspections.

Ultrasonic measurements have been successfully used for nondestructive materials characterization, including nondestructive evaluation (NDE) of degradation and damage [10], microstructure characterization [11], quantification and visualization of structural changes [12, 13] and process control [14]. Ultrasonic NDE is a critical element of the nuclear power industry's in-service inspection program for maintaining the integrity of the pressure boundary [15], and is being actively investigated for postirradiation examination of fuels [16]. Ultrasonic measurements, typically performed at $10 \mathrm{MHz}$ or higher [4], performed post irradiation show that fuel microstructural parameters, such as porosity and grain size, can be correlated to ultrasonic velocity $[5,16]$.

Ultrasonic methods historically have seen limited applicability to environments with high temperatures and irradiation. Though some environmental factors (such as temperature) affect the measurement (sound speed, for instance), the limitation is primarily due to the probes themselves. Most commonly, lead-zirconate-titanate (PZT) is used as the piezoelectric sensor material for ultrasonic nondestructive measurements. PZT is limited in its applicability at elevated temperatures (approximately above $300^{\circ} \mathrm{C}$ ). However, recent tests (through DOE-NE's NEET-ASI program) have identified a number of alternatives that can operate at elevated temperatures (in excess of $400^{\circ} \mathrm{C}$ ) and can survive irradiation [6]. Certain grades of PZT have also been demonstrated for use in imaging under-sodium in sodium fast reactors [12]. A number of prior studies have also examined piezoelectric sensor material survivability using in-pile sensor tests in materials test reactors and in ultrasonic characterization of irradiated fuel specimens $[4,5,8,16]$. Recent advances in high-temperature ultrasonic sensor design has led to ultrasonic sensors that have demonstrated survivability at $550^{\circ} \mathrm{C}$ for several weeks, under thermal cycling [17].

These advances in ultrasonic sensor design will be leveraged in this research. 


\section{TREAT}

TREAT (cutaway view shown in Figure 1. Cutaway of TREAT reactor.Figure 1) was constructed in the late 1950's and, after extensive use, was placed in standby in 1994 [18]. TREAT was designed to evaluate reactor fuels and structural materials under conditions simulating various types of nuclear excursions and transient undercooling situations in a nuclear reactor. Fuel meltdowns, reactions between coolant and metals (structural, fuel, or cladding), interaction between overheated fuel and coolant, and the transient behavior of fuels for high temperature systems can be studied. TREAT is an air-cooled reactor driven by a core of graphite blocks having a small concentration of dispersed uranium oxide. Prismatic columns of these graphite-fuel blocks are hermetically encapsulated in zirconium alloy sheet metal cladding. Aluminum-sheathed graphite reflector blocks at top and bottom of each fuel column form a fuel assembly with $1.2 \mathrm{~m}$ of active core length. Along with control rod, experiment, and graphite reflector assemblies, these fuel assemblies are placed on a $19 \times 19$ gridplate with 361 available positions; creating a configurable core that can be adjusted to suit particular nuclear parameters or experimental objectives [19]. 


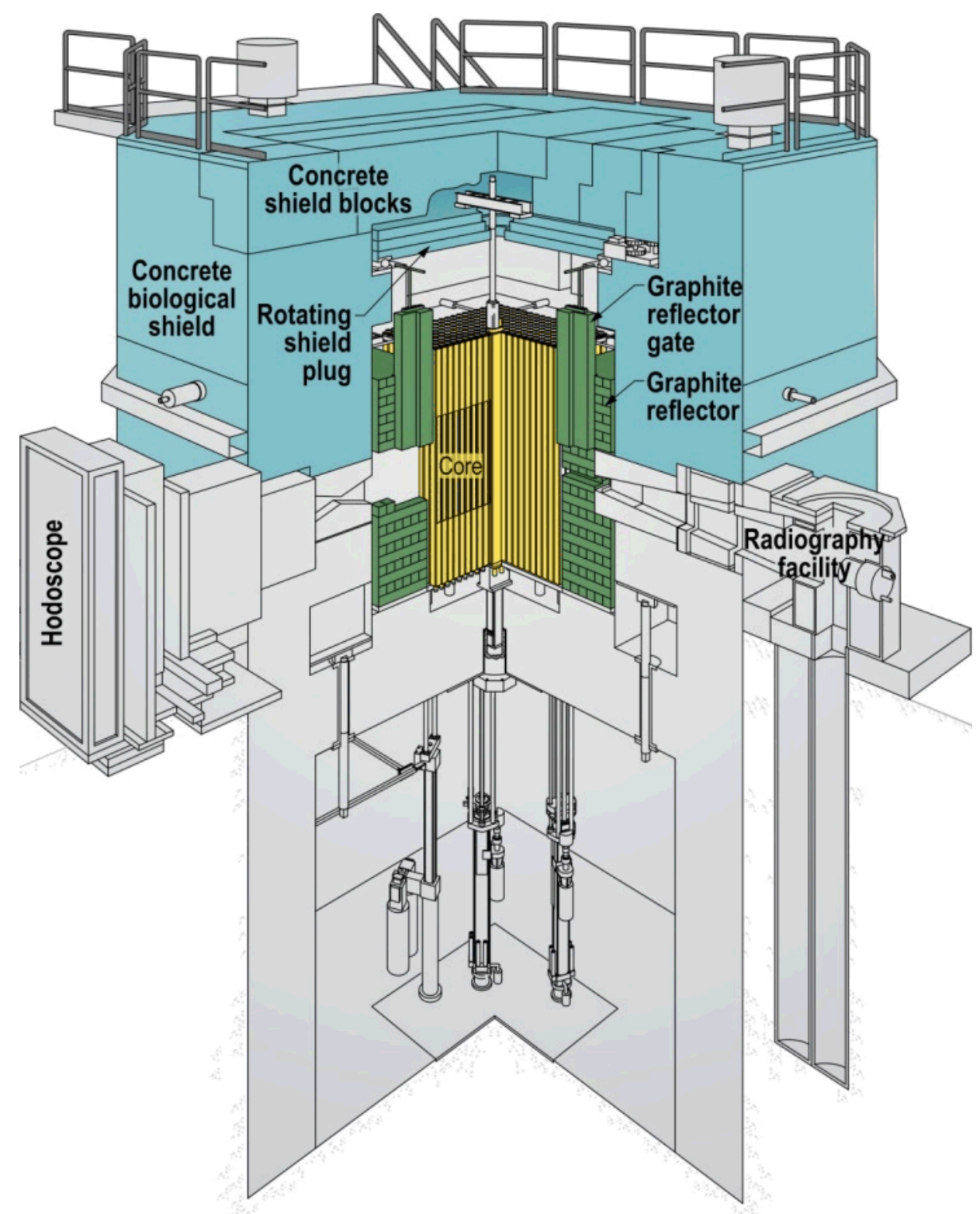

Figure 1. Cutaway of TREAT reactor.

A few fuel assemblies are typically removed from the central core positions to create a cavity for experiments (as shown in Figure 2). Experiment assemblies are typically removed from or placed into the core through a slot in the reactor's upper rotating shield plug, handled outside the reactor using shielded casks, and stowed below grade in storage holes when not in use. Four slots can be opened through the vertical concrete shield walls and permanent graphite reflector surrounding the above-grade core to provide various capabilities [20]. TREAT experiment rigs are, in essence, self-contained reactor vessels in which the neutrons are produced externally. Each rig (static capsule or loop) has its own double containment boundary and is simply lowered into the reactor test position, allowing for high throughput of experiments. 


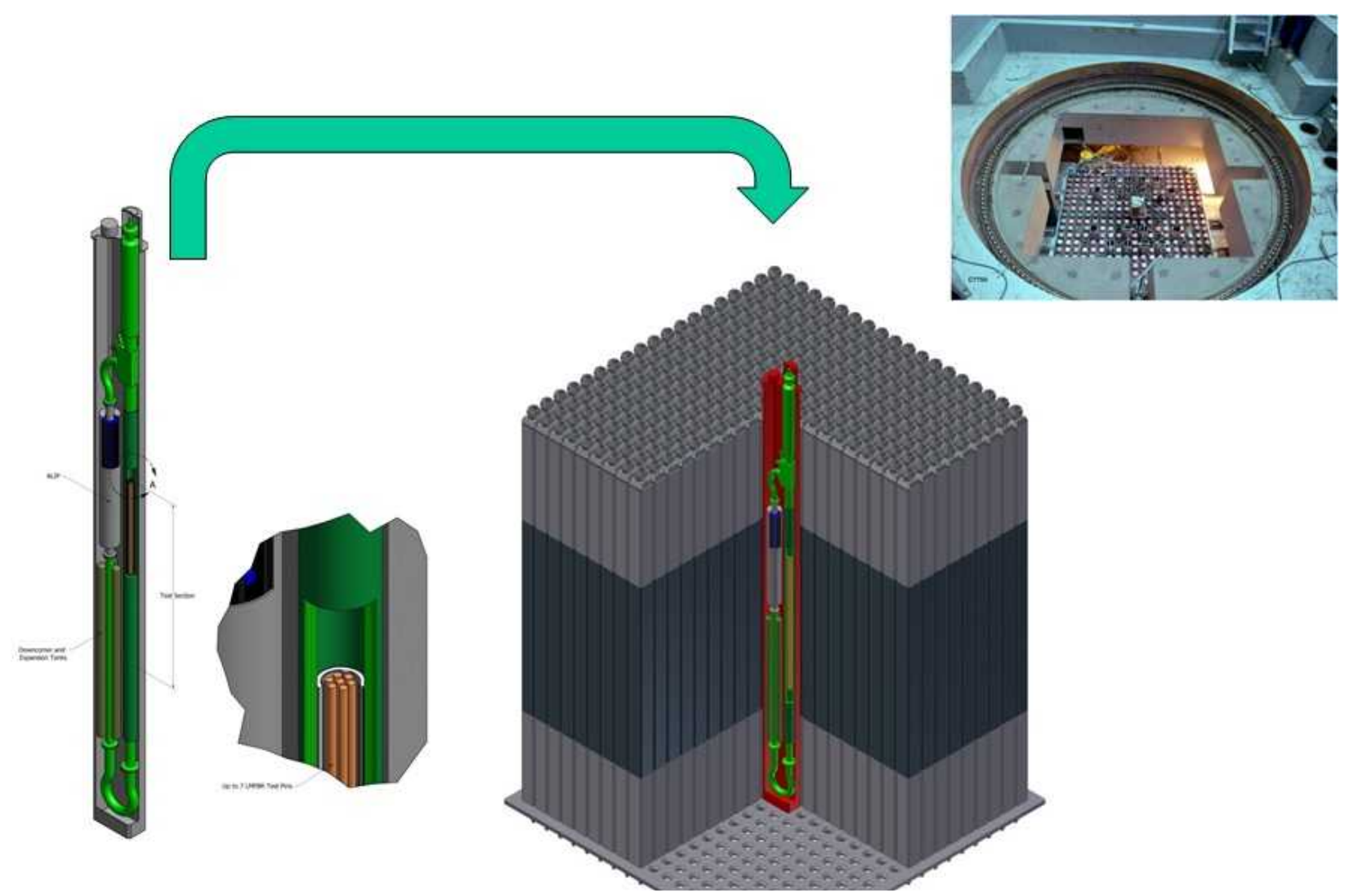

Figure 2. TREAT reactor central test position.

\subsection{Transients}

TREAT's transients can be shaped to vary over several orders of magnitude in terms of both reactor power and transient duration; the precise shape being practically governed simply by the core energy capacity (currently $2500 \mathrm{MJ}$ ). The shape of the TREAT is arbitrary, as long as the power/time profile is a function and the total integral energy is less than 2500 MJ. Figure 3 shows several simple transients which may be considered to encompass the extremes of TREAT transients in terms of power and duration [20]. 


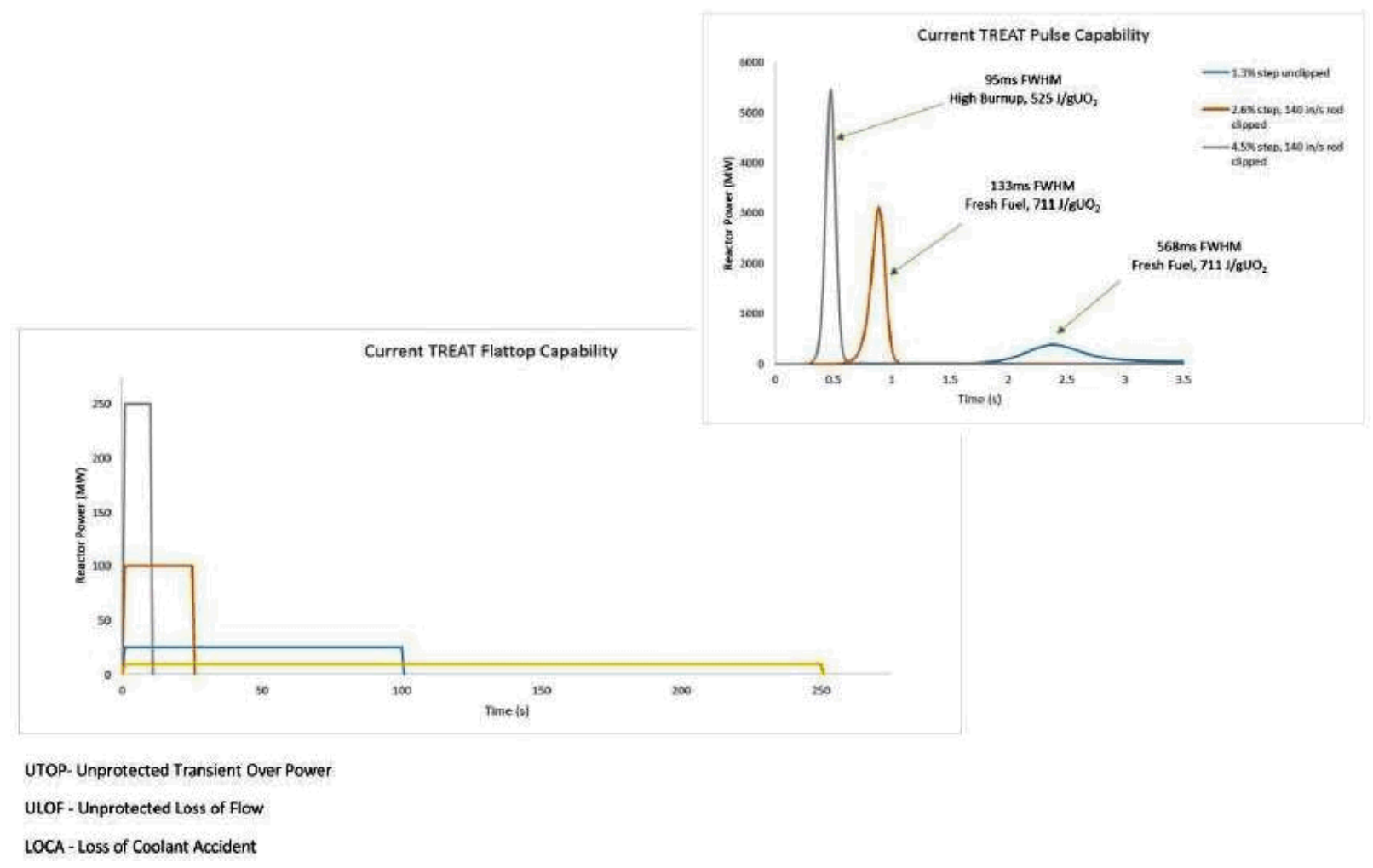

Figure 3. Shapes of typical power transients at TREAT.

\section{TREAT Experiment Capsules}

The initial testing, demonstration, and deployment of the ultrasonic deformation sensor are very likely to be performed using the near term TREAT testing capabilities of the MARCH system, described in the next few subsections. Other systems are under development, such as pressurized capsules and flowing water and sodium loops, but these are currently at the conceptual phase and will not be deployed for several years.

\subsection{The MARCH System}

An innovative approach to separate effects transient testing was conceptualized to leverage minor radioactivity built-in during brief TREAT irradiations by allowing for testing of small, previously unirradiated specimens in low activation hardware to enable easy extraction and shipping for PIE within weeks of irradiation. The concept was named the Minimal Activation Retrievable Capsule Holder (MARCH) irradiation vehicle system [20-22]. The modular nature of the MARCH system allows for remarkable flexibility in the design and execution of irradiation tests. As such, this system is an ideal testbed for a variety of sensors and materials. The MARCH system components are shown in Figure 4. 

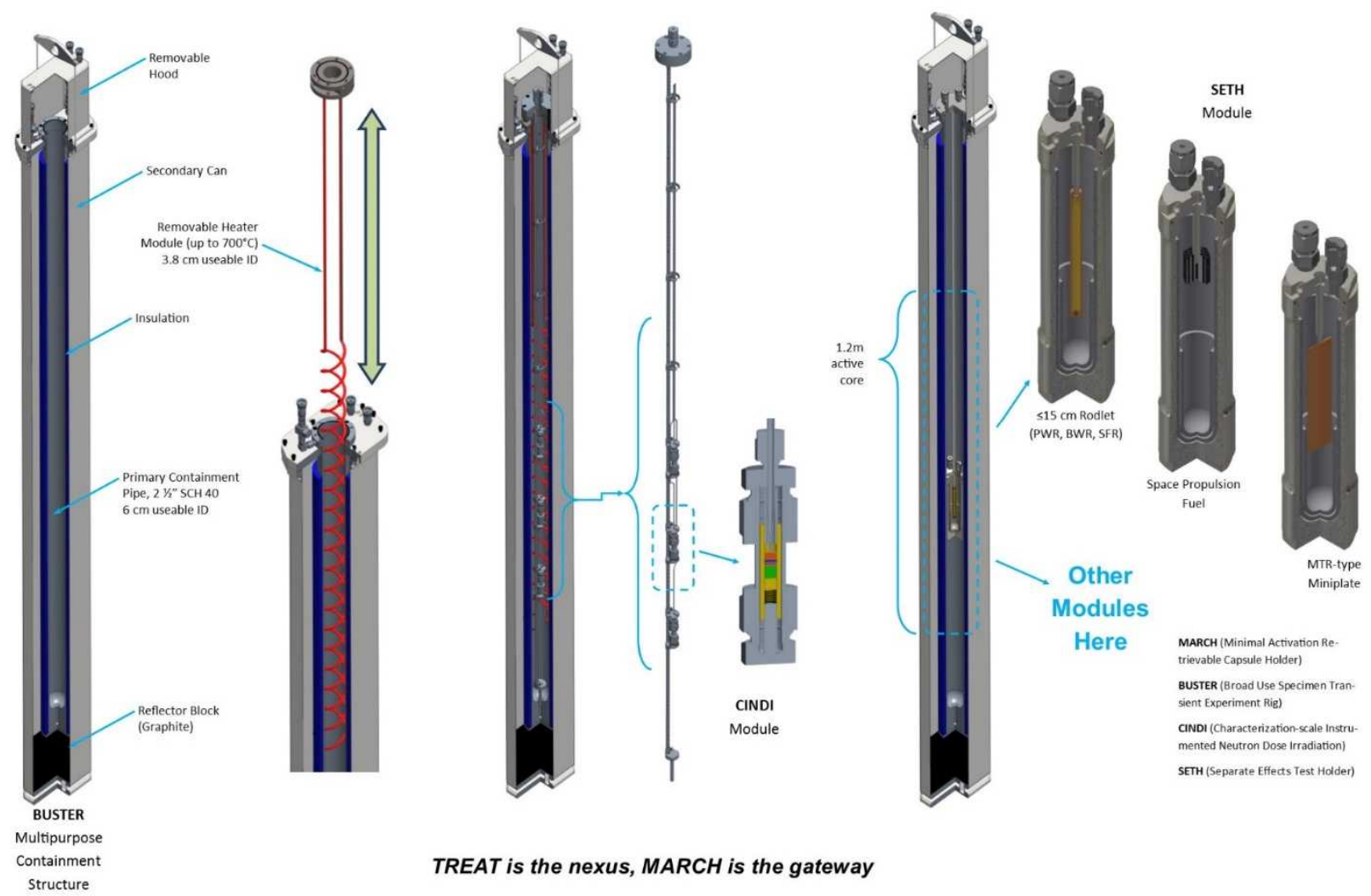

TREAT is the nexus, MARCH is the gateway

Figure 4. MARCH irradiation system components.

A key component allowing for the flexible, modularity of the MARCH system is the Broad Use Specimen Transient Experiment Rig (BUSTER) [20-22]. The BUSTER provides primary and secondary containment for experiments using the MARCH system. This is necessary as the reactor itself does not provide for containment, and experiments containing pre-irradiated fuels require double containment. The major benefit of this design is that the experiment capsules (described below) themselves can be designed and fabricated to a lower level of rigor. This allows for savings in both financial and time when carrying out an experiment. Compression seals in both the primary pipe flange and upper plate of the hood are used to hermetically route instrument and power leads through the top where support lines can be connected. Purge gas can also be supplied to the experiment through lines plumbed into the hood and pipe flange. The BUSTER primary containment pipe also can be outfitted with an electric heating coil (Figure 5) to provide steady-state pre-irradiation temperatures of up to $700^{\circ} \mathrm{C}$. The pipe can also be used, in some instances, as a stand-alone test capsule, with or without the removable hood and sealing flange pictured in Figure 6 and Figure 7. This is only the case for benign testing (some instruments/sensors, for example). 

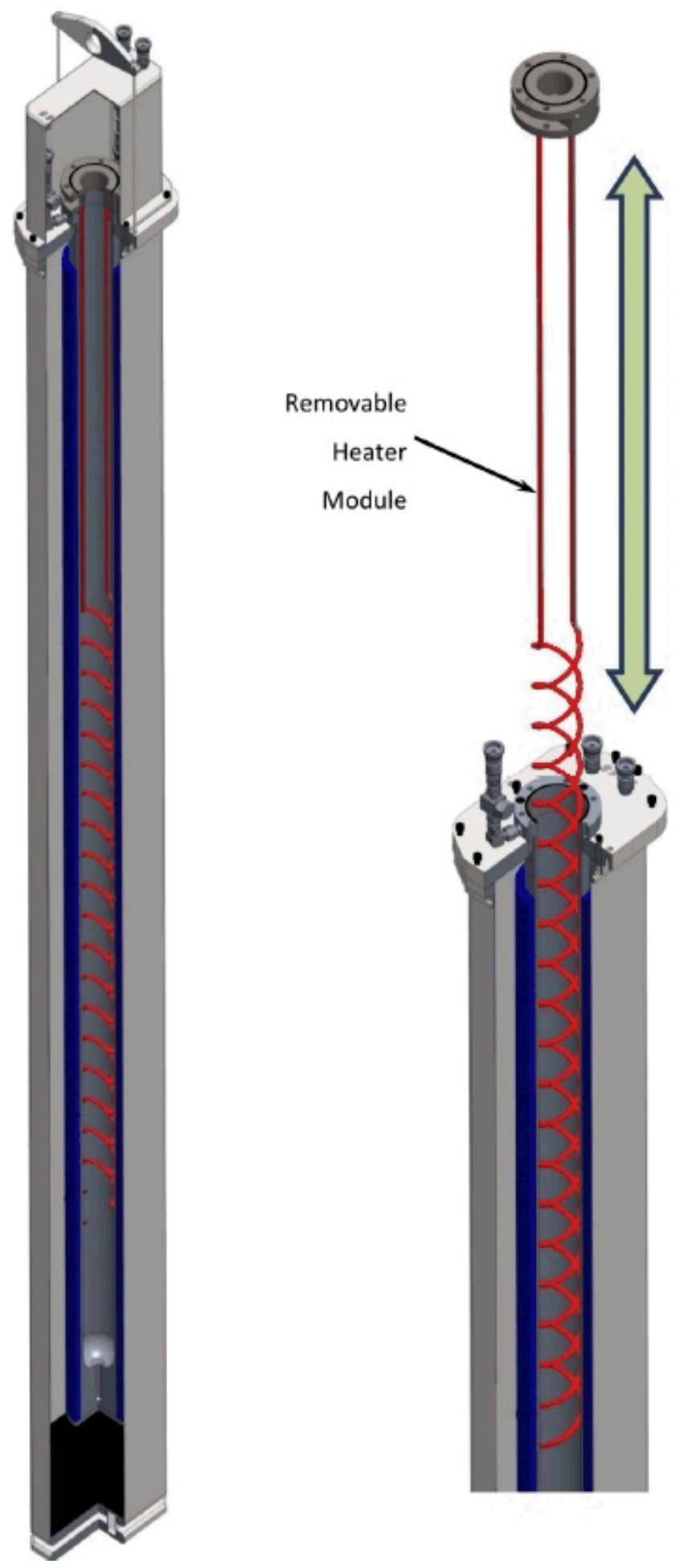

Figure 5. BUSTER with heater coil installed. 


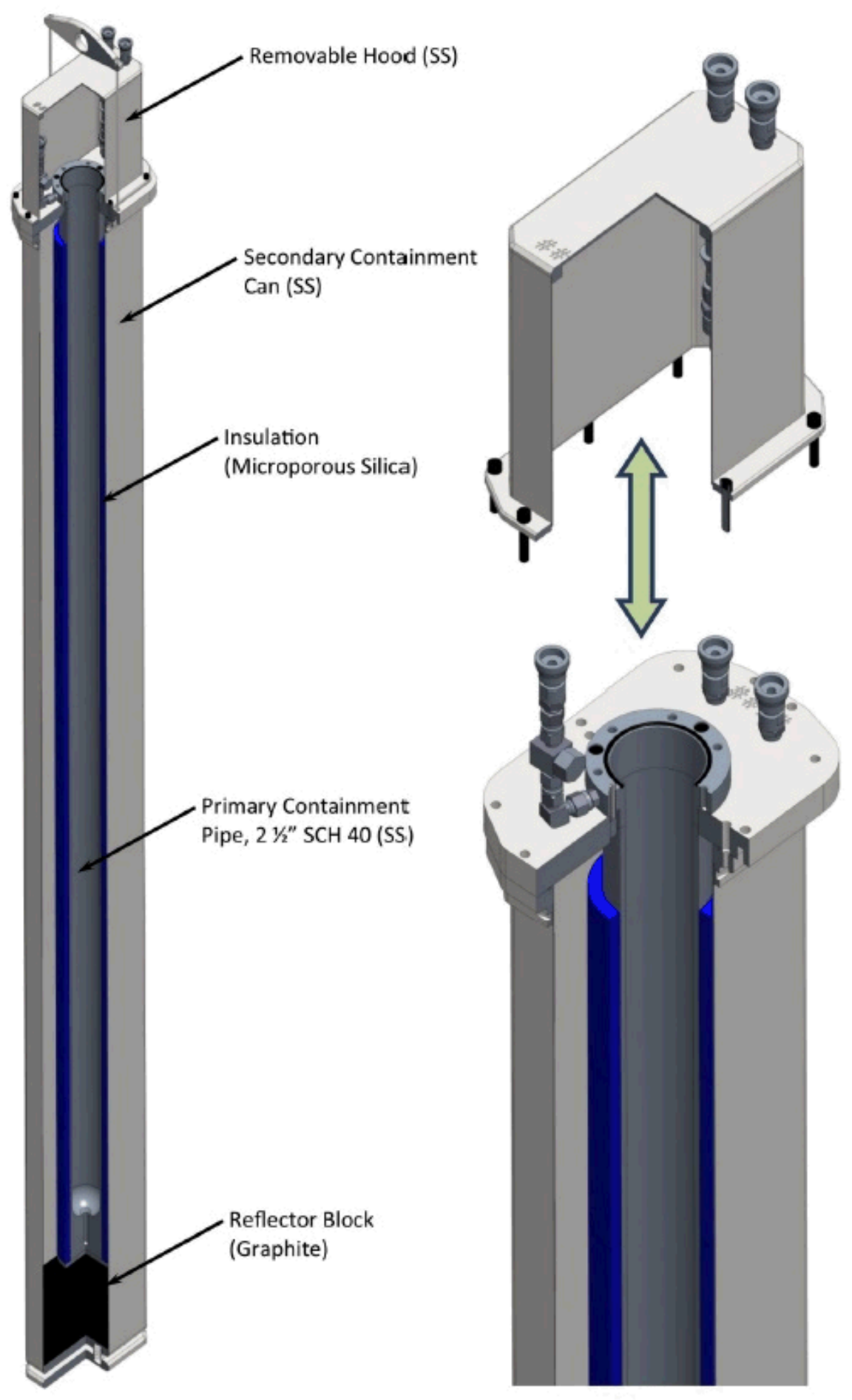

Figure 6. BUSTER secondary containment can and primary containment pipe. 

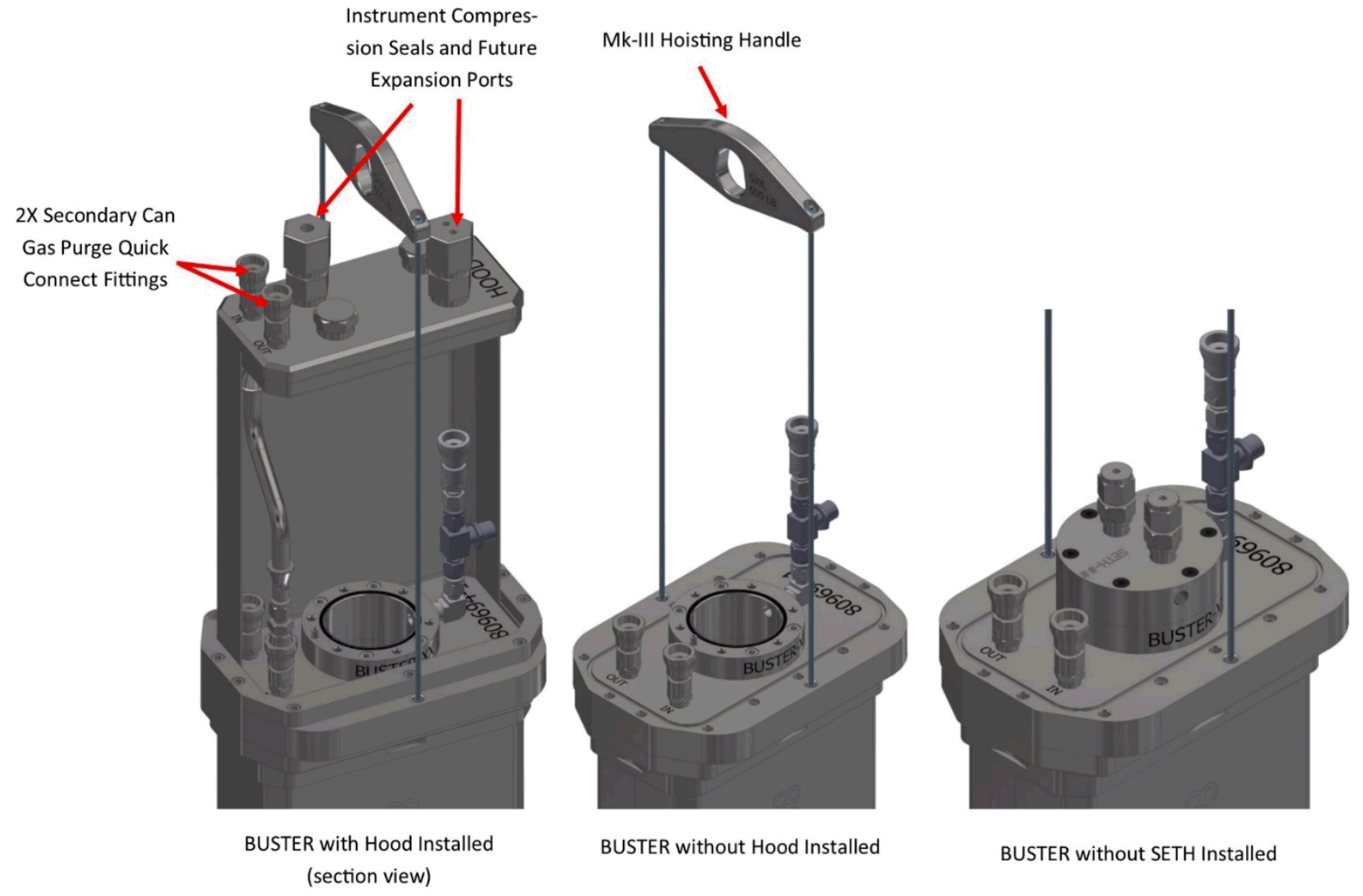

Figure 7. BUSTER top enclosure configurations.

\subsubsection{CINDI}

The Characterization-scale Instrumented Neutron Dose Irradiation module (CINDI) module can be used for irradiation of small fuel or other material samples in well-controlled and monitored temperature conditions [20-22]. CINDI capsules (Figure 8) can house a small stack of disc-like material specimens $5 \mathrm{~mm}$ in diameter. The CINDI samples are meant to be useable with standard material property characterization equipment. As an example, a single CINDI experiment can irradiate samples for postirradiation laser flash, differential scanning calorimeter, microscopy, and dilatometer evaluation. Although the CINDI is not appropriate for testing of real time, active sensor elements, it could be used for screening of piezoelectric materials. 


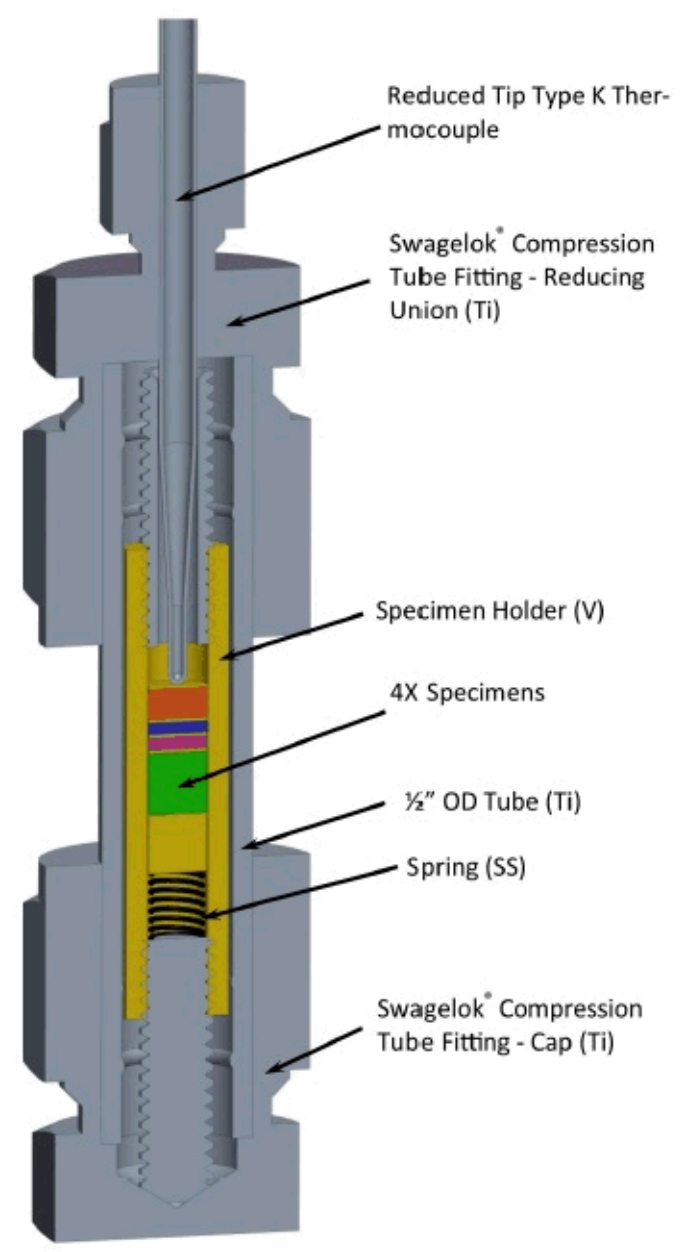

Figure 8. CINDI capsule with material irradiation samples.

\subsubsection{SETH}

The Separate Effects Test Holder (SETH), shown in Figure 9, is somewhat larger than CINDI and does not allow for the use of the BUSTER heater system (a smaller heater may still be used) [20-22]. It does, however, contain sufficient volume for testing several forms of fuel samples, including LWR rodlets, MTR style plate fuels, etc., in non-prototypic sizes. The space available can also accommodate significant instrumentation, with feedthroughs using standard compression seals which can accommodate multiple $1 \mathrm{~mm}$ diameter MIMS cables. The SETH module does not currently include the capability for prototypic reactor coolant conditions (e.g. hot pressurized water, liquid sodium, etc.), but a room temperature, atmospheric pressure, water environment is planned. SETH has been identified as an ideal testbed for many applications including:

- Screening survivability tests. First round of testing for sensor in TREAT.

- Testing of sensor for sensitivity to reactor effects and signal noise characterization.

- Qualification testing with surrogate samples to demonstrate sensor performance.

Figure 10 shows a more detailed view of the SETH lid illustrating one planned test configuration. Aluminum structures are used for holding the central test specimen (a fuel rodlet or surrogate) as well as the instrumentation. These holders may be specially designed for different configurations and specimens, giving the SETH module tremendous flexibility for testing sensors in a variety of configurations. 


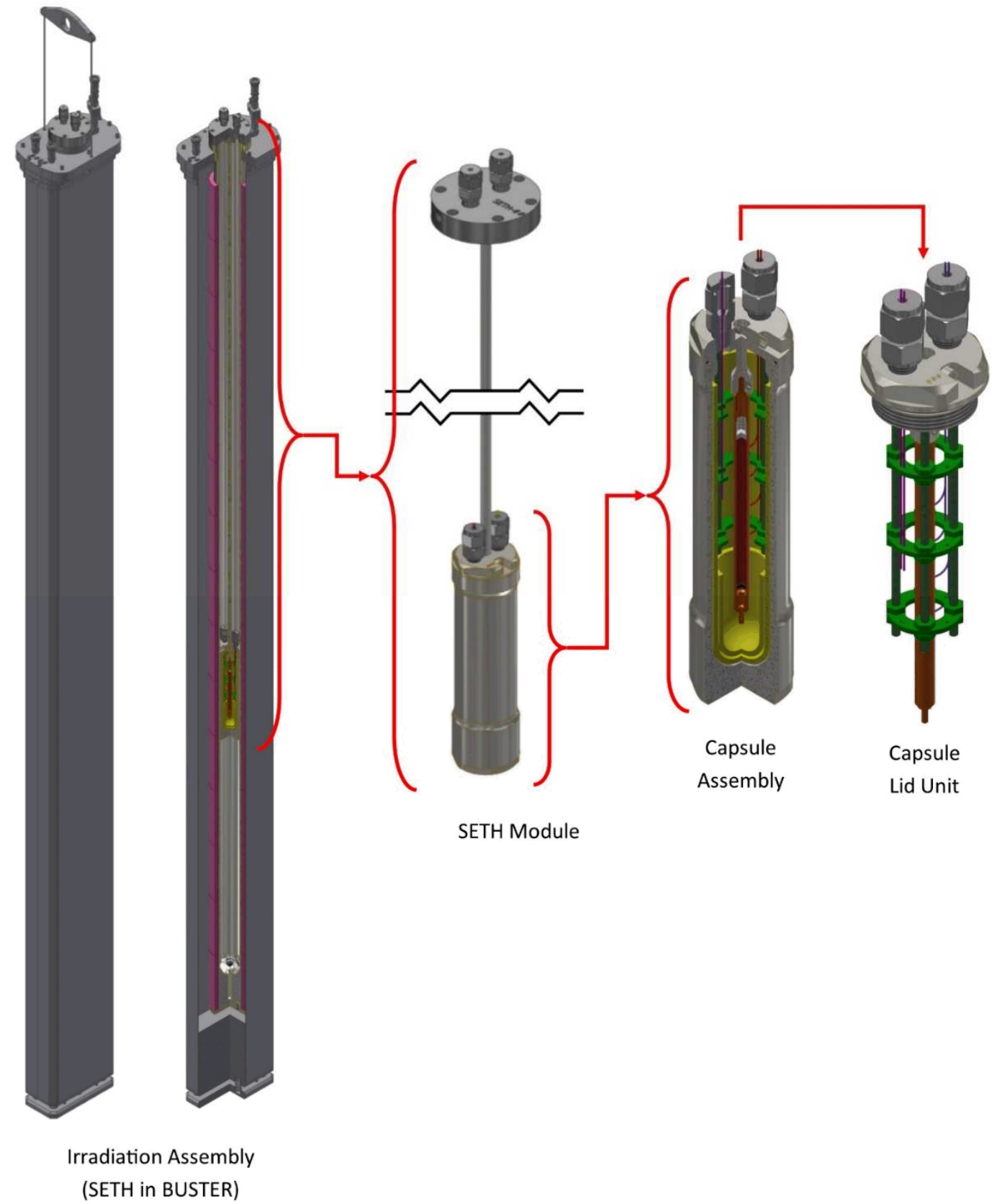

Figure 9. SETH module and integration within BUSTER. 


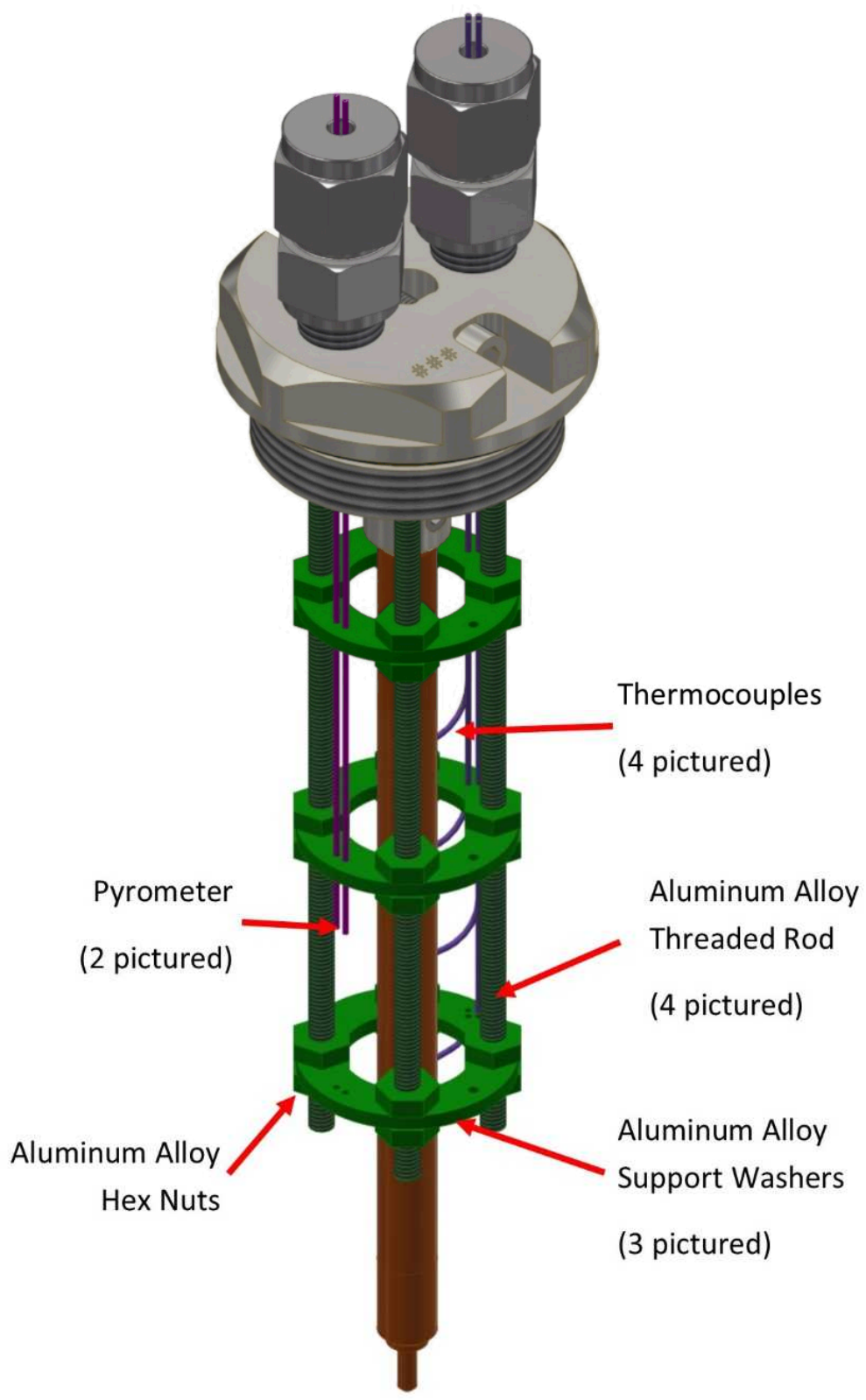

Figure 10. SETH capsule internal sensor supports and fuel pin surrogate.

\subsubsection{THOR}

The Temperature Heat-sink Overpower Response (THOR) module is designed to act as a heat sink for samples, simulating a loop type boundary condition without the need for a flowing coolant loop [2022]. The THOR module is installed within the BUSTER primary containment pipe, with a small diameter heater as needed $\left(400^{\circ} \mathrm{C}\right.$ maximum temperature). The fuel specimens are thermally coupled to the titanium heat sink via molten sodium. As such, there is little room inside the capsule for radial deformation sensors. However, it is possible to mount a sensor on the outer wall of the heat sink, acoustically coupling to the fuel rodlet through the titanium and sodium. Although there is also little room between the THOR outer wall and the BUSTER pipe, this module is still in the design phase and could be modified slightly to accommodate installation of sensors. Figure 11 shows a schematic drawing of the THOR module. 


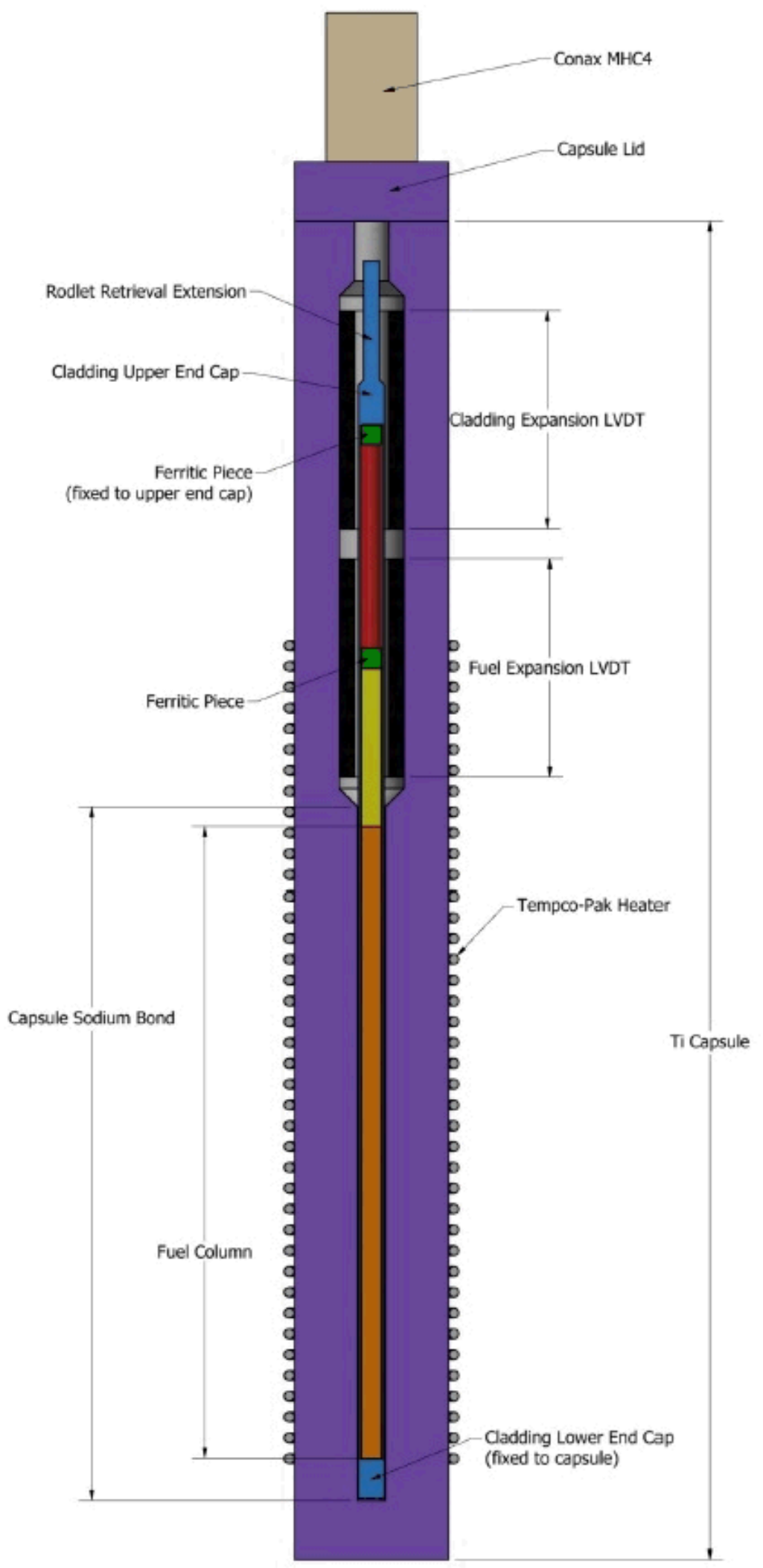

Figure 11. THOR capsule schematic with sodium bonded fuel pin. 


\subsection{Reactor Drop-In Positions}

In addition to experimental test positions and purpose built test capsules, TREAT also offers simplified access to its coolant channels for the testing of small diameter sensors or materials. At the corners of the square cross section fuel blocks are $15 \mathrm{~mm}$ square coolant channels, through which air is circulated [19]. Specially designed instrument test rods have been developed to allow installation of various sensors into these channels. The tubes are 0.25 inch outer diameter and 0.18 inch inner diameter. The tubes may be sealed on the end or left open, to allow a sensor too large to fit into the tube to hang below. The closed ended tube is 88 inches long. The instrument rod can be fitted with a standard Conax or Swagelok fitting at the top which is used to anchor the sensor or signal cable. To date, legacy SPNDs (used previously in TREAT) and optical fibers have been installed and tested. The instrument rods may be useful for rapid screening of materials and acoustic coupling strategies. Figure 12 shows the reactor top installation of instrument test rods into cooling channels in the TREAT reactor.

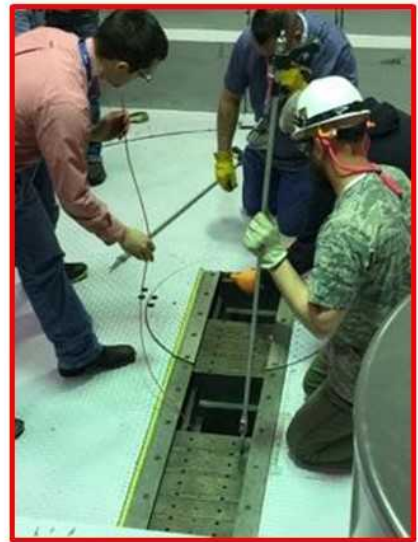

Experimenters lowering instrument rods into reactor with shield blocks removed

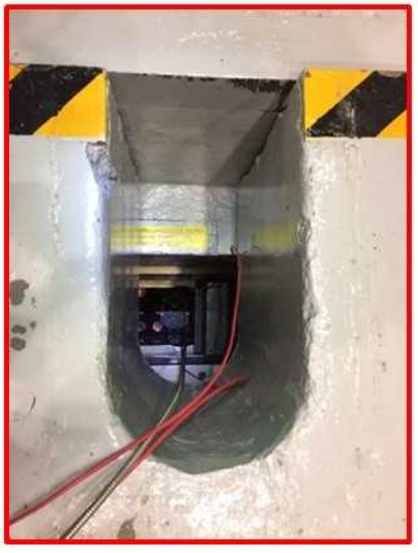

Instrument rods installed in reactor with shield blocks in place

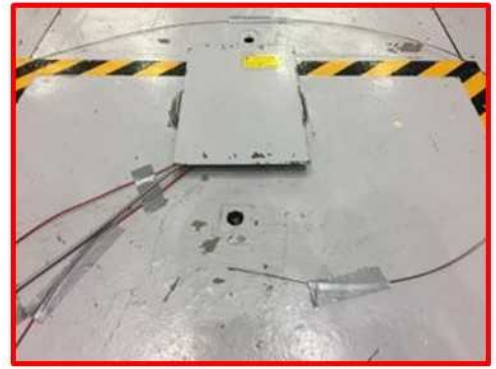

Reactor top experiment access

Figure 12. Installation of instrument test rods in TREAT cooling channels.

\section{Functional Requirements}

The measurement parameters of interest for this project are axial and radial deformation of irradiation samples, primarily LWR type fuel rodlets. Several of the planned irradiation tests will use LVDTs for making axial measurements. So, although axial deformation is still of interest, radial deformation of fuel and fuel cladding is of most importance. Program leads have also expressed interest in other parameters that may be measureable by an ultrasonic sensor. Although the sensor will be actively used for dimensional measurements, onset of boiling will lead to a notable change in acoustic coupling with the sample. As such, the sensor may be useful as a boiling detector. Passive detection of signals related to boiling characteristics, clad failure, acoustic emissions (fuel cracking) may also be possible. 


\subsection{Review of Cladding Strain Measurement Requirements for TREAT Testing Capability}

This section contains a short discussion of the expected ranges of cladding strain, strain rate, and temperature that a system of real-time strain measurement would need to accommodate to provide data of interest during power pulse testing in the TREAT reactor. This review relies on previous testing and analytical evaluations performed to assess the behavior of fuel rods, both Light Water Reactor (LWR) and Fast Reactor (FR), under conditions of rapid energy deposition caused by an insertion of neutron reactivity (Reactivity Initiated Accident - RIA).

\subsubsection{LWR Fuel Behavior During RIA}

The nuclear industry and the NRC have spent considerable resources from 1990's to around 2010 to study the behavior of LWR fuel (zirconium alloy cladding and uranium dioxide fuel) under RIA conditions. This arose because of the tests performed in the 1990's on fuel that had extreme end of life conditions of high burnup and low cladding ductility from corrosion. Some of these rods exhibit brittle fracture type failure modes at low strain levels, contrary to the behavior observed in tests with zero or lower burnup and limited cladding corrosion. Questions were raised regarding the need to establish a limit on the postulated RIA event to ensure that LWR plants would meet all safety criteria (specifically 10CFR50 Appendix A GDC 28).

A review of the RIA data on LWR fuel performed in 2003-2004 identified the following characteristics of cladding mechanical behavior in fuel tested under RIA-like conditions [23].

"One of the primary objectives of performing RIA-simulation experiments and the resulting post-test evaluations is to determine the conditions leading to cladding failure. In this context, the results of this evaluation have found that fuel behavior during a RIA power pulse can be divided into two phases as shown in Figure 5. Phase 1 corresponds to the prompt energy deposition of the power transient and compromises $\sim 60$ to $95 \%$ of the power pulse, depending on the pulse width, amount of energy deposition, and pellet-cladding gap size. During Phase 1, the fuel pellet heat-up due to the energy deposition is close to adiabatic conditions with only a small amount of heat conduction to the cladding. The radial average peak fuel enthalpy generally occurs during Phase 1 when more than $90 \%$ of the energy deposition occurs in the prompt power pulse. In Phase 1, the pellet expands by thermal expansion and, depending on the gap thickness, causes pellet-cladding mechanical interaction (PCMI). As governed by the condition of the cladding to accommodate the PCMI loading, cladding failure can occur during Phase 1. The test rod failures in CABRI and NSRR included in this evaluation all experienced cladding mechanical fracture in Phase 1 in the course of the prompt energy deposition.

Phase 2 corresponds to the delayed energy deposition portion of the power transient, where heat conduction becomes a dominant mechanism. The heat conduction to the cladding in Phase 2 causes an increase in the cladding temperature, and depending on the coolant conditions, can initiate DNB at the cladding surface. Increases in cladding temperature improve the cladding ductility and decrease the cladding yield strength. Depending on the amount of energy deposition or the occurrence of DNB, cladding temperatures can exceed $600{ }^{\circ} \mathrm{C}$ in Phase 2. Under these conditions, the cladding yield strength decreases substantially and the cladding becomes more susceptible to deformation by processes other than PCMI." 


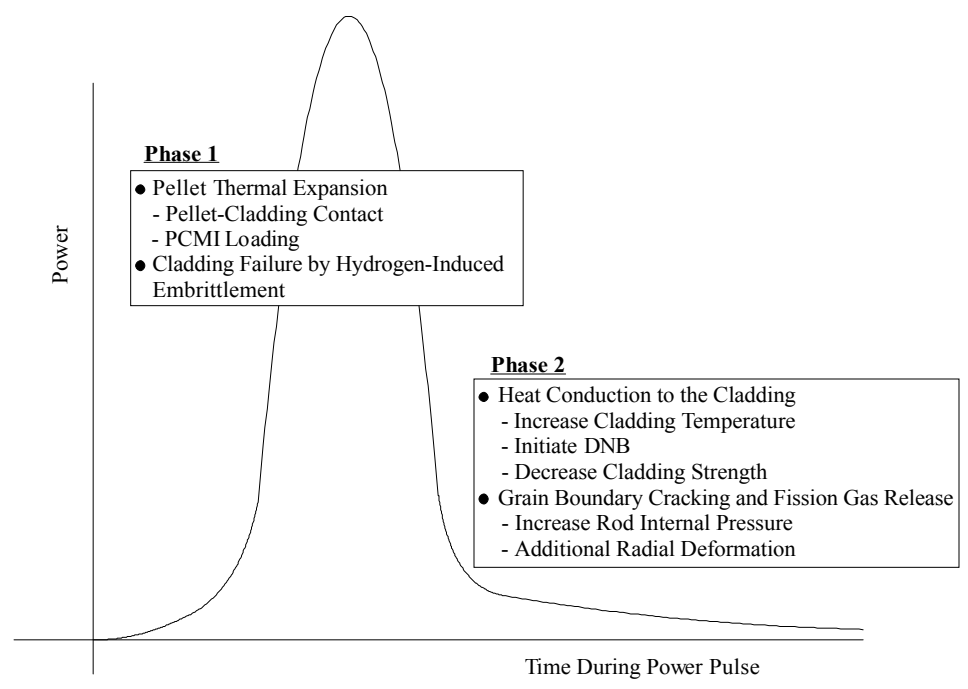

Figure 13. Schematic of Phase 1 and Phase 2 of the Clad Loading Process During an RIA Power Pulse

The take-away from these observations is that the mechanical response of the cladding during a RIA event is composed of complex interacting processes, including mechanical loading, heat transfer, and deformation.

The strain experienced by several RIA tests are shown in Table 1. For those that failed during the test, the calculated strain at failure is listed along with the calculated maximum strain. For tests that failed during the Phase 1 processes described above, the strain at failure is less than $1 \%$ (or radial deformations less than 50 microns). If the test rod survived Phase 1, then additional cladding strain accumulates with measured values up to values of $10-11 \%$ (deformations of 500 microns).

Another important variable shown in Table 1 is the cladding temperature during an RIA test from both model calculations and measurements. The maximum temperature depends somewhat on the starting coolant temperature $\left(280^{\circ} \mathrm{C}\right.$ for sodium tests and $25^{\circ} \mathrm{C}$ for water tests), but it also depends on the heat transfer conditions during the test as well. For tests performed in water, the maximum temperature is influenced by the occurrence of departure from nucleate boiling (DNB), which significantly reduces the heat transfer between the cladding and the coolant. This results in high temperatures being reached at some time after the power pulse is completed. For tests with thermocouple measurements, cladding temperatures exceeding $600^{\circ} \mathrm{C}$ were observed for those tests that experienced DNB. 
Table 1. Cladding Diametral Strain Data from LWR RIA Test Rods.

\begin{tabular}{|c|c|c|c|c|c|}
\hline Case & $\begin{array}{l}\text { Calculated } \\
\text { Peak Hoop } \\
\text { Strain } \\
\text { [at failure] } \\
(\%)\end{array}$ & $\begin{array}{c}\text { Measured } \\
\text { Strain } \\
(\%)\end{array}$ & $\begin{array}{l}\text { Peak ID } \\
\text { Cladding } \\
\text { Temp. }+ \\
\left({ }^{\circ} \mathrm{C}\right)\end{array}$ & $\begin{array}{c}\text { Calculated Peak } \\
\text { OD Cladding } \\
\text { Temp. }+ \\
\text { [fail }],\{\mathrm{EP}\} \\
\left({ }^{\circ} \mathrm{C}\right)\end{array}$ & $\begin{array}{c}\text { Measured } \\
\text { Peak } \\
\text { Cladding } \\
\text { OD Temp. } \\
\left({ }^{\circ} \mathrm{C}\right)\end{array}$ \\
\hline \multicolumn{6}{|c|}{ CABRI PWR RIA Experiments, $280^{\circ} \mathrm{C}, 0.5 \mathrm{MPa}$ flowing $\mathrm{Na}$} \\
\hline $\mathrm{Na}-5$ & 1.21 & 1.04 & 747 & $\{432\} 519$ & $390-400 *$ \\
\hline $\mathrm{Na}-8$ & {$[0.69] 1.1$} & 0.83 & {$[557] 682$} & $\{303\}[370] 483$ & $\mathrm{n} / \mathrm{a}$ \\
\hline $\mathrm{Na}-10$ & {$[0.67] 1.0$} & failed & {$[521] 725$} & {$[316]\{494\} 502$} & $\mathrm{n} / \mathrm{a}$ \\
\hline CIPO-1 & 0.92 & 0.4 & 686 & $\{476\} 481$ & $\mathrm{n} / \mathrm{a}$ \\
\hline \multicolumn{6}{|c|}{ NSRR PWR RIA Experiments, $25^{\circ} \mathrm{C}, 0.1 \mathrm{MPa}$ stagnant water } \\
\hline HBO-5 & {$[0.86]$} & failed & {$[450] 500$} & {$[34]\{73\} 198$} & $\mathrm{n} / \mathrm{a}$ \\
\hline HBO-6 & 0.93 & 1.5 & 545 & $\{71\} 206$ & 170 \\
\hline $\mathrm{HBO}-7$ & 0.97 & 1.7 & 553 & $\{80\} 215$ & 165 \\
\hline TK-1 & 1.67 & 25 & 573 & $\{97\} 247$ & 600 \\
\hline TK-2 & {$[0.60]$} & failed & [292] 637 & {$[29]\{82\} 233$} & $\mathrm{n} / \mathrm{a}$ \\
\hline TK-3 & 1.15 & 5.6 & 594 & $\{77\} 221$ & 715 \\
\hline TK-4 & 1.14 & 4 & 554 & $\{98\} 230$ & $\sim 600$ est \\
\hline TK-5 & 1.19 & 4 & 545 & $\{95\} 230$ & $\sim 600$ est \\
\hline TK-6 & 1.64 & 16 & 635 & $\{111\} 261$ & 705 \\
\hline $\mathrm{TK}-7$ & {$[0.95]$} & failed & {$[529] 562$} & {$[35]\{74\} 214$} & $\mathrm{n} / \mathrm{a}$ \\
\hline \multicolumn{6}{|c|}{ NSRR BWR RIA Experiments, $25^{\circ} \mathrm{C}, 0.1 \mathrm{MPa}$ stagnant water } \\
\hline FK-1 & 1.71 & 0.85 & 709 & $\{44\} 257$ & 350 \\
\hline FK-2 & 0.67 & 0 & 412 & $\{44\} 147$ & $\mathrm{n} / \mathrm{a}$ \\
\hline FK-3 & 1.99 & 1.47 & 742 & $\{46\} 272$ & 600 \\
\hline FK-4 & 1.78 & 1.25 & 809 & $\{58\} 292$ & 610 \\
\hline FK-5 & 0.66 & 0 & 443 & $\{56\} 156$ & $\mathrm{n} / \mathrm{a}$ \\
\hline FK-6 & {$[0.71]$} & 0.1 & [89] 638 & {$[28]\{37\} 249$} & $\mathrm{n} / \mathrm{a}$ \\
\hline FK-7 & {$[0.62]$} & 0.1 & {$[155] 715$} & {$[28]\{50\} 261$} & $\mathrm{n} / \mathrm{a}$ \\
\hline FK-8 & 0.61 & 0 & 383 & $\{35\} 138$ & $\mathrm{n} / \mathrm{a}$ \\
\hline FK-9 & {$[0.94]$} & 0.38 & {$[375] 562$} & {$[30]\{42\} 194$} & $\mathrm{n} / \mathrm{a}$ \\
\hline
\end{tabular}

\$ Temperatures and cladding response without DNB. Cladding OD temperatures at failure are provided in brackets [ ], and the OD temperatures at end of prompt pulse energy deposition in \{\} , with the peak OD temperature.

* REP Na 5 Temperature Measurements are for local sodium coolant temperatures.

\subsubsection{Fast Reactor Fuel Behavior During RIA}

In order to test the safety-related behavior of metal fuels for use in the Integral Fast Reactor, tests of metal-alloy fuels sodium bonded to cladding comprised of one of a variety of steels [24] were performed within a sodium loop constructed within TREAT from 1985 to 1987 and were monitored with the hodoscope, thermocouples, and flowmeters. Transient overpower tests were conducted with full coolant flow and an exponential power rise on an 8 second period. In total, 19 fuel pins were tested and cladding failure occurred in 5 of these tests. The pins that were tested had one of three fuel types (U-5FS (where FS is fissium, a mixture of metals representing an equilibrium composition of fission products after 
reprocessing), U-19Pu-10Zr, or U-10Zr) and one of 3 cladding types (316 SS, D9, or HT9). Each pin had been irradiated in EBRII to a burnup between 0 and 9.8 atom \%. The typical results from an instrumented test resemble the suite of plots below.
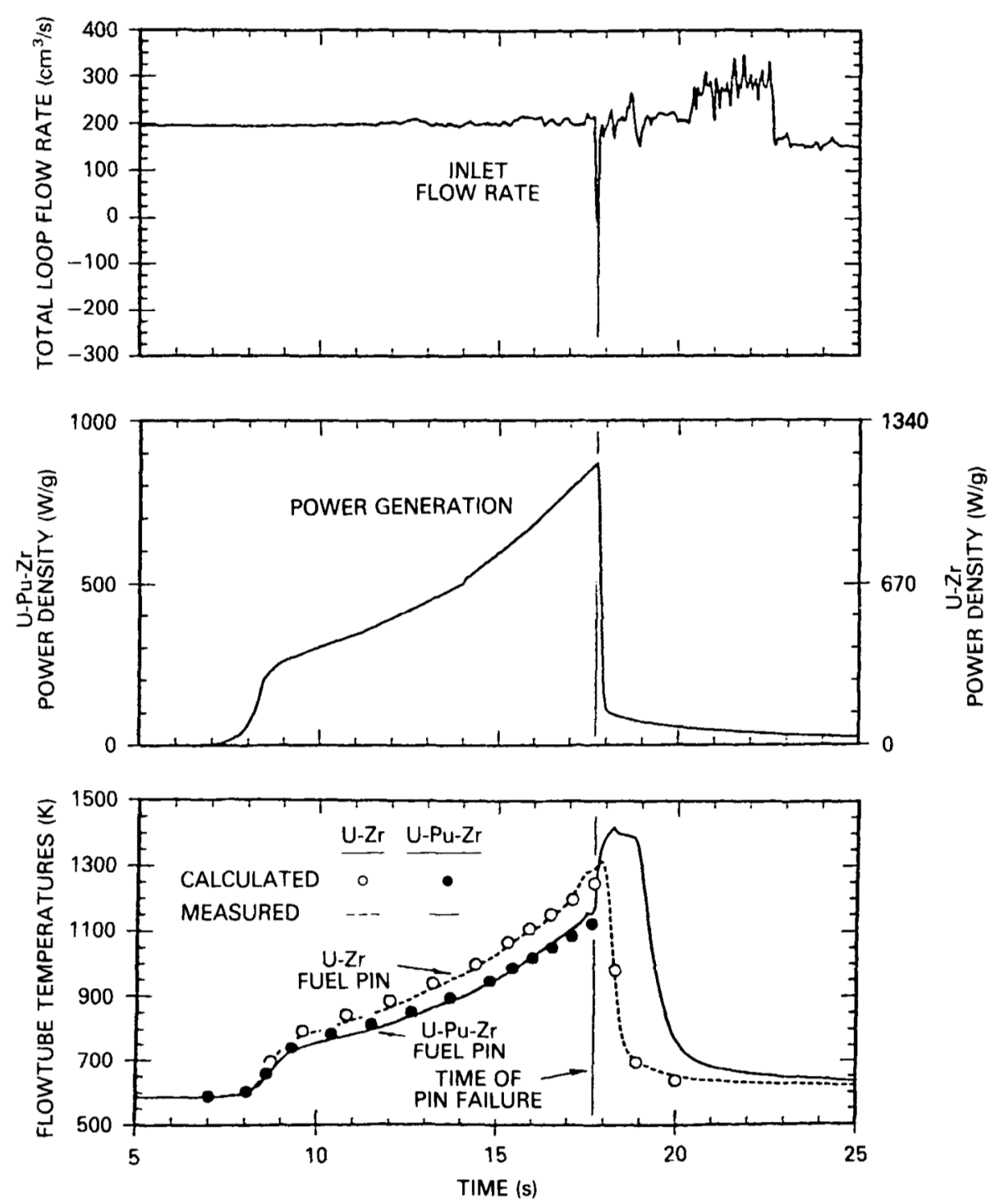

Figure 14. Selected test results for fast reactor fuel, illustrating a typical sequence for initiating fuel pin failure (from [24])

Additionally, axial expansion of the pin, as well as fuel density was tracked with the hodoscope during the test and compared to static pre- and post-test measurements with the hodoscope. Post-test characterization of the axial expansion and density was also examined with radiography and cross sections of the fuel were examined with microscopy post-test to assess clad thinning, eutectic/interaction layer formation between the fuel and cladding, fuel melting front, and gas bubble distribution. 


\subsection{Dimensional Measurement requirements}

TREAT transients range in power from $19 \mathrm{GW}$ pulses to $100 \mathrm{~kW}$ steady state operation with durations from $\sim 100 \mathrm{~ms}$ to hours [19]. In order to capture transient phenomena with suitable resolution, sampling rates for dimensional data must be substantially faster than the minimum transient duration. Conversations with design leads indicate that sampling rates of $1000 \mathrm{~Hz}(1 \mathrm{~ms}$ period) or faster are needed.

The discussion in Section 5.1 indicates that the anticipated strain ranges for fuel transient tests is a function of how the fuel rod fails, and the heat transfer conditions. The samples of most importance are LWR and SFR fuel rodlets. Given that the expected cladding strain at failure can be less than $1 \%$ (or radial deformations less than 50 microns), the ultrasonic sensor is anticipated to be capable of measuring radial expansion between 0 to $200 \mu \mathrm{m}$ over the full transient duration. At this level of deformation, a resolution of $\pm 5 \mu \mathrm{m}$ is needed to ensure adequate confidence in the measured values, especially early in the transient test. During potential accident condition testing (i.e. rodlet ballooning due to overpressurization), the expected range of deformation is $0-5 \mathrm{~mm}$. The desired accuracy at this level of deformation is $\pm 0.1 \mathrm{~mm}$.

\section{Operational Requirements}

The minimum requirements for sensor deployment into the SETH test capsule are summarized in Table 1 .

Table 1. Minimum requirements for SETH capsule sensor testing in TREAT.

\begin{tabular}{|l|l|l|}
\hline Parameter & Requirement & Comment \\
\hline Sampling rate & $1000 \mathrm{~Hz}$ & Short pulsed transient \\
\hline \multirow{2}{*}{ Measurement resolution } & $\pm 5 \mu \mathrm{m}$ & Typical test \\
\cline { 2 - 3 } & $\pm 0.1 \mathrm{~mm}$ & Accident simulation \\
\hline $\begin{array}{l}\text { Maximum temperature of } \\
\text { operation }\end{array}$ & $600^{\circ} \mathrm{C}$ & TREAT fuel safety limit \\
\hline \multirow{2}{*}{\begin{tabular}{l} 
Chemical compatibility \\
\multirow{2}{*}{$\begin{array}{l}\text { Dimensional constraints } \\
\text { (SETH exterior mounting) }\end{array}$}
\end{tabular}} & Inert gas, air, water, steam & $\begin{array}{l}\text { Initial testing; sodium, liquid metals, molten salts may } \\
\text { follow }\end{array}$ \\
\cline { 2 - 3 } & $55.6 \mathrm{~mm}$ diameter & Inner diameter of BUSTER pipe \\
\cline { 2 - 3 } & $122.93 \mathrm{~mm}$ & Outer diameter of SETH capsule (necked region) \\
\hline $\begin{array}{l}\text { Dimensional constraints } \\
\text { (SETH interior mounting) }\end{array}$ & $46.9 \mathrm{~mm}$ & Length of SETH capsule (necked region) \\
\cline { 2 - 3 } & $209.6 \mathrm{~mm}$ & Inner diameter of SETH capsule \\
\hline
\end{tabular}

It is anticipated that the ultrasonic sensor will need to be placed either in the capsule in contact with the rodlet or outside the capsule. In either case, and especially in the case where the sensor is located outside the capsule, a mechanism for transferring energy from the sensor to the rodlet for strain measurement will be necessary. From the perspective of ultrasonic measurements, this is an issue with efficiently coupling energy across one or more boundaries (sensor-capsule, capsule-coolant, coolantrodlet, etc.). The coupling efficiency will be influenced by the conditions at the interfaces as well as the conditions in the media through which the energy has to pass. For example, in the case of a water-cooled transient test, boiling of the water will reduce coupling efficiency for a sensor located outside the capsule. A detailed assessment of the potential options for sensor placement is being performed and will be reported in an upcoming deliverable. 
Currently, data acquisition systems for experimental sensors (not reactor control sensors) are temporarily located in a room adjacent to the reactor hall. The room (called the "Experimenter's Room) was historically used for instrumentation, but has been converted to a conference room. The Experimenter's room offers convenient access for signal line installation, as there is an underfloor trench that runs under the Experimenter's room wall to the concrete wall of the reactor. Adjacent to the reactor top is a mezzanine, which also may be used for temporary staging of electronics in the event that cable lengths must be minimized. Permanently installed systems are located in the facility data acquisition room. The locations of the Experimenter's room, reactor, trench, mezzanine, and facility instrument room are detailed in Figure 15. TREAT reactor facility floor plan. and Figure 16. Plan view of TREAT reactor and floor.

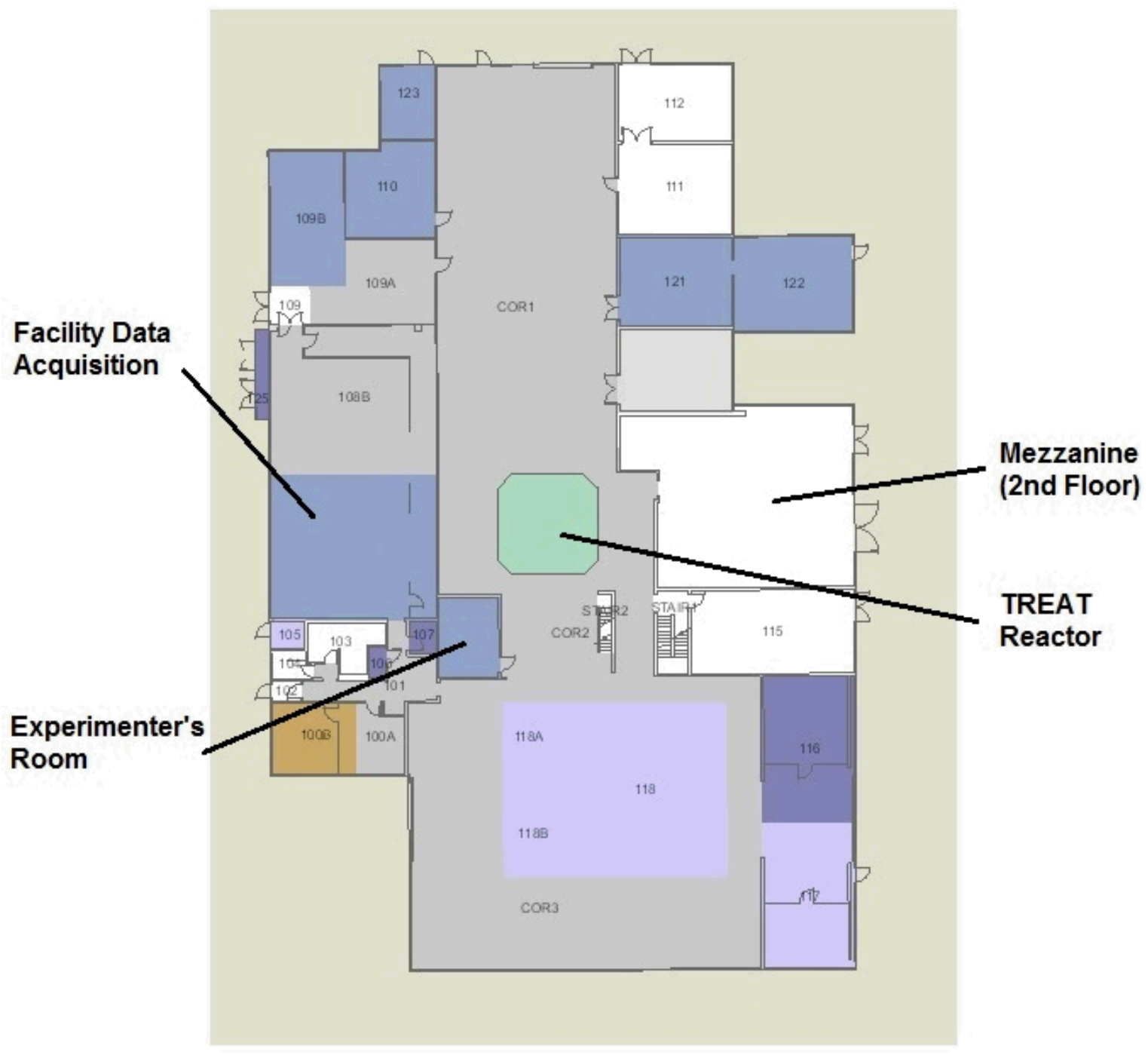

Figure 15. TREAT reactor facility floor plan. 


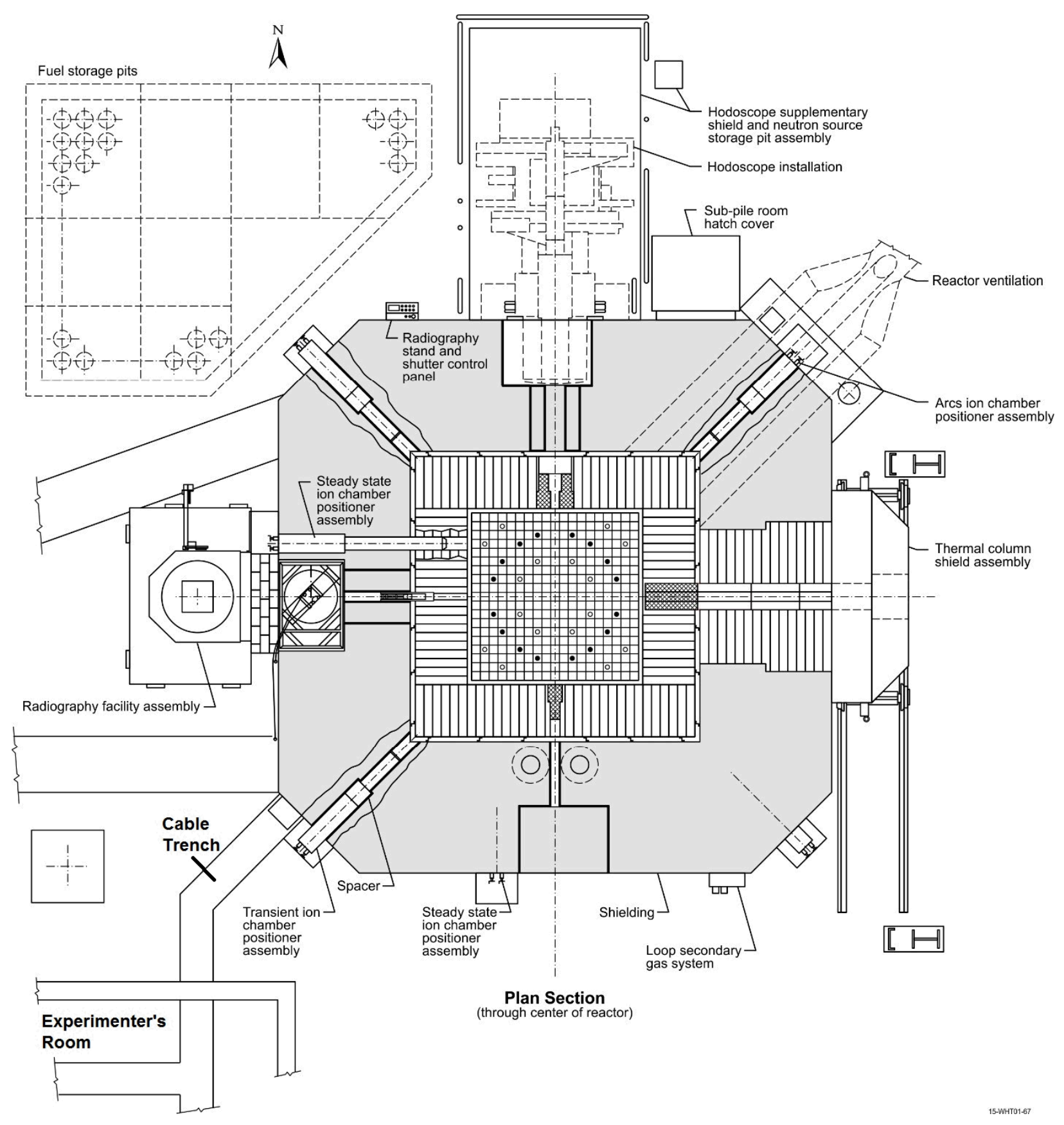

Figure 16. Plan view of TREAT reactor and floor.

Several conduit lines have been installed leading from the reactor hall floor to the reactor top. Cables are routed from the data acquisition system, through the trench, up the conduit and across the reactor top to a hole in the shielding corresponding to the experiment position. The routing and cable lengths are shown in Figure 17. Cable routing diagram. The in-core connector shown in the figure is optional. Experiments which must be loaded using a transfer cask can either accommodate a sensor with the optional connector or a sensor with a length of signal cable coiled at the top of the experiment. Electronics not considered primary data acquisition (i.e. pre-amplifiers) may be placed on the reactor top during testing. A new junction box (position shown in Figure 18. Current cable routing installations.) will 
allow for installation of these electronics once installation is complete. It is even possible to locate some electronics within the reactor shielding, but these systems will not be recoverable.

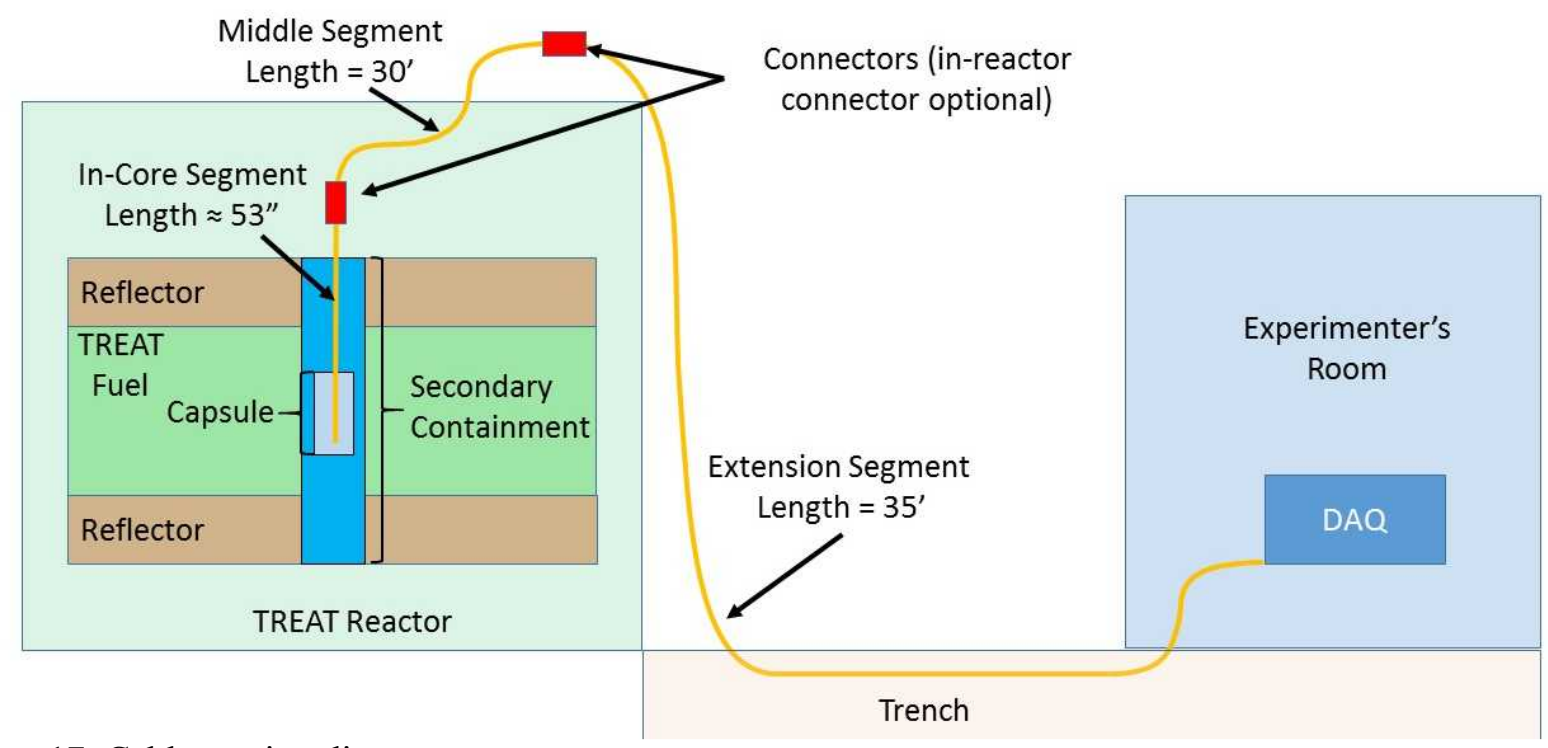

Figure 17. Cable routing diagram.

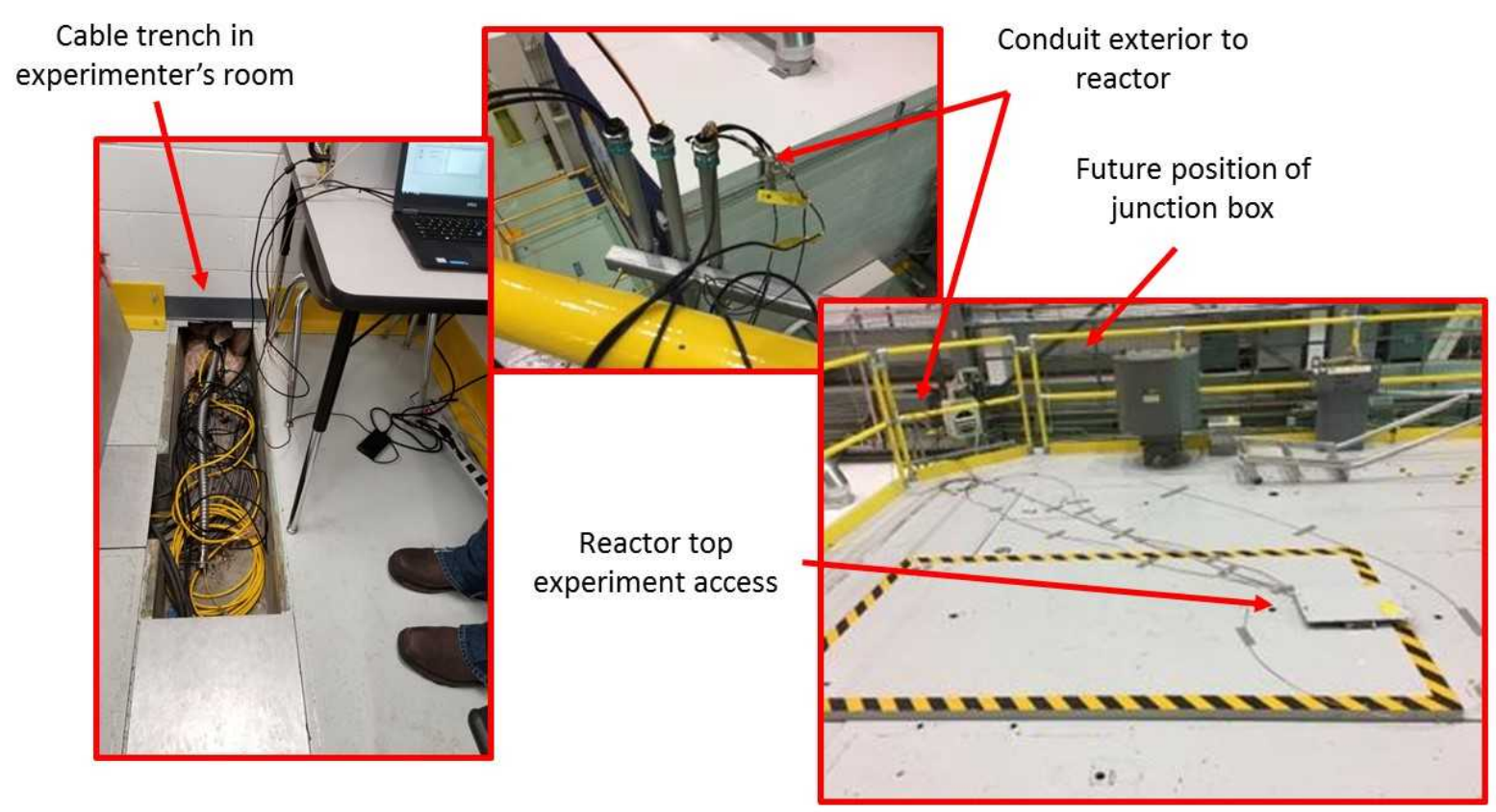

Figure 18. Current cable routing installations.

At this stage in the sensor design, it is anticipated that a standard ultrasonic pulser-receiver (such as a UTEX-340 or a Ritec-4000) will be sufficient for the measurement. A high-power, high-output impedance amplifier may be necessary on the front end to maximize power supplied to the sensor, while a pre-amplifier may be needed to boost signal levels during reception. The data acquisition system will likely consist of an off-the-shelf digitizer with a computer for control and data storage. The critical 
requirement for the instrumentation is high sampling rates and a high ultrasonic pulse repetition frequency (PRF).

As many of the proposed irradiations will involve pre-irradiated fuel, installation of the sensor in a hot cell may be necessary in some cases. Installation on the outer surface of a test capsule (i.e. SETH or THOR) can be performed prior to transfer of the capsule to the hot cell. For near term testing, SETH is the capsule which would require internal placement of the sensor. SETH uses the previously described hanger structures attached to the lid for placement of instrumentation. As such, the sensor could be installed and affixed to the lid prior to transfer to the hot cell. The sensor must either be carefully aligned prior to transfer or the hanger structure must be designed to allow for in cell alignment.

Given the unknown effects of high flux, short duration neutron and gamma radiation, some initial material effect testing in the TREAT facility may be required. The CINDI capsule and availability of instrument test rod installation in cooling channels should be leveraged for measurement of material properties and online performance of piezoelectric transducers.

\section{Summary}

This report is meant to be a guiding document for the development of an ultrasonic deformation sensor to be deployed in TREAT transient experiments. As such, information detailing the reactor, likely experiment capsules, and facilities have been included. Also, information on the required measurement speed and resolution and design constraints have been documented through literature reviews and interactions with TREAT team leads. Development of this document has shown that although there are many potential applications, each with variations on design and needs, there are several basic constraints that need to be met for any application. The SETH capsule has been selected as a first target application, as it is planned for near term deployment, matches most of the design considerations of other planned capsules, and is designed to be used for sensor testing, along with fuel and material irradiations. 


\section{References}

1. C. Jensen, et. al., "FY17 Report for Instrumentation Development for the Transient Testing Program,” INL/EXT-17-43444, Sept., 2017.

2. Colby Jensen, "Experiment Instrumentation for Transient Testing," Advanced Sensors and Instrumentation 2016 NE I\&C Review, Oct. 12-13, 2016

3. C. Jensen, "Transient testing instrumentation needs," Presented at the 2016 DOE-NE ASI Program Review, October 2016.

4. D. Fourmentel, J. F. Villard, et al, "Acoustic sensor for in-pile fuel rod fission gas release measurement," in First Int'l. Conf. on ANIMMA, 2009, pp. 1-5.

5. K. K. Phani, D. Sanyal, and A. K. Sengupta, "Estimation of elastic properties of nuclear fuel material using longitudinal ultrasonic velocity - A new approach," J. Nucl. Mater., vol. 366, pp. $129-136,6 / 30 / 2007$.

6. J. Daw, J. Rempe, et al., NEET In-Pile Ultrasonic Sensor Enablement-Final Report, Technical Report, PNNL-23746 (INL/EXT-14-32505), 2014.

7. P. N. Bilgunde and L.J. Bond, "Effect of Thermal Degradation on High Temperature Ultrasonic Transducer Performance in Small Modular Reactors," Physics Procedia 70:433-436, 2015.

8. R. Jacobs, P. Ramuhalli, and A. Casella, "Characterization of microstructural differences in irradiated nuclear fuel using ultrasonic NDE," IEEE Trans. UFFC (In preparation).

9. Ramuhalli P, R Jacob, P MacFarlan and A Casella. 2017. "Microstructural Characterization of Irradiated U0.17ZrH1.6 Using Ultrasonic Techniques." Trans. ANS 116(361-364).

10. D. Ensminger and L. J. Bond, Ultrasonics: Fundamentals, Technologies, and Applications, 3rd ed.: CRC Press, 2012.

11. P. Ramuhalli, R. V. Harris, et al., "In-situ Characterization of Cast Stainless Steel (CASS) Microstructures," ed. Berlin, Germany, 2010.

12. M. R. Larche et al, "Progress in the development and demonstration of a 2D-matrix phased array ultrasonic probe for under-sodium viewing," AIP Conf. Proc., Vol. 1706, Issue 1, 2016.

13. D. R. Weier, and A. F. Pardini, Evaluation of UT Wall Thickness Measurements and Measurement Methodology, Technical Reprot, Pacific Northwest National Laboratory, PNNL16828 , Oct 2007.

14. L. C. Lynnworth, Ultrasonic Measurements for Process Control: Theory, Techniques, Applications: Elsevier Science, 2013.

15. S. R. Doctor, "Nuclear Power Plant NDE Challenges - Past, Present, and Future," presented at the Review of Progress in Quantitative Nondestructive Evaluation, Portland, Oregon, 2007.

16. D. Baron, D. Laux, and G. Despaux, "Mechanical characterisation of irradiated fuel materials with local ultrasonic methods," in Pellet-clad Interaction in Water Reactor Fuels, 2004.

17. Prowant M, G Dib, H Qiao, M Good, M Larche, S Sexton and P Ramuhalli. 2017. "Preliminary Design of High Temperature Ultrasonic Transducers for Liquid Sodium Environments." In Review of Progress in Quantitative Nondestructive Evaluation, Provo, UT.

18. "FUTURE Transient Testing of Advanced Fuels," Summary of the May 4-5, 2009 Transient Testing Workshop Held at Idaho National Laboratory, 2009.

19. "TREAT Baseline Description Document," ANL/RAS 72-23, Aug., 1972.

20. N. Woolstenhulme, C. Baker, J. Bess, D. Chapman, C. Jensen, C. Hill, D. Wachs, S. Wilson, "Status Report for NEET In-Pile Sensor Irradiation Capabilities at TREAT," INL/EXT-17-43274, Sept., 2017

21. N.E. Woolstenhulme, "Update on TREAT Restart and Experimental Design Preparations," OSU IRP Meeting November 2017, Corvallis, WA.

22. Dan Wachs, "Status of Transient Testing Capabilities in the United States," GAIN Workshop on Fuel Safety Research, Idaho Falls, ID, May1-5, 2017. 
23. D. Sunderland, et. al., "Evaluation of Recent RIA-Simulation Experiments with the FALCON Fuel Performance Code," Proceedings of the 2004 International Meeting on LWR Fuel Performance, Orlando, FL, 2004.

24. Bauer et al., BEHAVIOR OF METALLIC FUEL IN TREAT TESTS, Nuclear Technology, Vol. 92, 1990. 